\title{
The Dual Role of Sirtuins in Cancer
}

\author{
Laia Bosch-Presegué ${ }^{1}$ and Alejandro Vaquero ${ }^{1,2}$
}

@SAGE

\begin{abstract}
Among the greatest challenges facing organisms is that of detecting and effectively responding to life-threatening environmental changes that are intimately associated with metabolic fluctuations and certain forms of stress. These conditions have been linked to the onset of many human pathologies, including cancer. Over the past decade, members of the Sir2 family, or sirtuins, have been described as major players in sensing and coordinating stress response. Evidence has imputed mammalian sirtuins in carcinogenesis, although the mechanisms involved seem to be more diverse and complex than previously anticipated. Some sirtuins, such as SirT2 and SirT6, seem to work as tumor suppressors, but others, such as SirT1, are apparently bifunctional: operating as both tumor suppressors and oncogenic factors depending on the context and the study conditions. The mechanisms underlying these apparently contradictory activities are not well understood, although recent findings suggest that they might actually be two sides of the same coin. In this review, the authors summarize current knowledge on the functional implications of sirtuins in cancer and discuss possible explanations for their functional duality.
\end{abstract}

Keywords: sirtuins, cancer, genome stability, deacetylation, SirT1-7, heterochromatin, DNA repair, DNA damage

0 ver the past decade, the members of the Sir2 family, or sirtuins, have garnered tremendous attention in biomedical research. The founder member of the family, yeast Sir2p, was originally identified in Saccharomyces cerevisiae as a factor involved in rescue of mating deficiency. ${ }^{1}$ Sir $2 p$ is involved in the epigenetic silencing of matingtype loci, nucleolar rDNA, and telomeres, ${ }^{2,3}$ through establishment of a heterochromatin-like compact structure in which the $\mathrm{N}$-terminal tails of histones $\mathrm{H} 3$ and $\mathrm{H} 4$ are hypoacetylated. ${ }^{4,5}$ The significance of Sir2p function is reflected by the established link between Sir2p, longevity, and genome stability. ${ }^{4}$

Sirtuins are present from bacteria to humans. ${ }^{6}$ Although they have diversified and acquired new functions throughout evolution, their main functions seem to be to detect changes in the redox state of the cell resulting from stress (whether oxidative, metabolic, or genotoxic) and to coordinate an adequate response. Sirtuins are $\mathrm{NAD}^{+}$-dependent protein deacetylases and mono-[ADP-ribosyl] transferases. ${ }^{7-9}$ The ability of sirtuins to sense energy fluctuations in the cell is linked to their requirement of $\mathrm{NAD}^{+}$as a cofactor for enzymatic activity. Sirtuins are defined by their homology to the catalytic domain of Sir2p, which spans approximately 250 residues. Sirtuins differ in their specificity and catalytic activity. For example, some seem to show ADP-ribosyltransferase activity, yet not all of them have detectable deacetylase activity. Although most sirtuins seem to have a broad range of histone and nonhistone protein substrates, some of them are strictly specific histone deacetylases (HDACs), whereas others seem to target nonhistone proteins. ${ }^{3,10-13}$ Mammalian sirtuins, also referred to as class III HDACs, comprise 7 members (SirT1-7) that differ widely in their localization, activity, and functions. SirT1, 6, and 7 are mainly nuclear; SirT2 and SirT3 are mainly cytoplasmic and mitochondrial, respectively, although both are present in limited levels in the nucleus; and SirT4 and 5 are strictly mitochondrial. ${ }^{3,12-14}$ Some sirtuins can relocalize in function of cell or tissue type, developmental stage, metabolic status, and certain stress conditions, suggesting that localization is important for regulating their function. Mammalian sirtuins perform myriad functions that can be classified according to 4 processes: chromatin regulation, cell survival under stress, metabolic homeostasis regulation, and developmental and cell differentiation. ${ }^{15}$ The consequences of energy imbalance have been consistently associated with the onset and/or development of many human pathologies. Consistent with sirtuins playing an important role in this response at both the cellular and organism levels, they have been linked to cancer, diabetes, cardiovascular diseases, and neurodegenerative diseases, among other maladies.

Sirtuins apparently play contradictory roles in cancer, as illustrated in recent findings. ${ }^{14,16,17}$ On one hand, some sirtuins help protect DNA (from damage and oxidative stress), maintain genomic stability, and limit replicative life span, all of which suggest that they would protect organisms against cancer. On the other hand, some data suggest that promotion of cell survival under stress conditions by sirtuins could be directly involved in tumorigenesis, as it would inhibit senescence and allow

${ }^{1}$ Chromatin Biology Laboratory, Cancer Epigenetics and Biology Program (PEBC), Institut d'Investigació Biomèdica de Bellvitge (IDIBELL), Barcelona, Spain ${ }^{2}$ ICREA (Institut Català de Recerca i Estudis

Avançats), Barcelona, Spain

\section{Corresponding Author:}

Alejandro Vaquero, Chromatin Biology Laboratory, Cancer Epigenetics and Biology Program (PEBC), Institut d'Investigació Biomèdica de Bellvitge (IDIBELL), Av. Gran Via de l'Hospitalet, 199-203, 08908 L'Hospitalet de Llobregat, Barcelona, Spain Email: avaquero@idibell.cat 


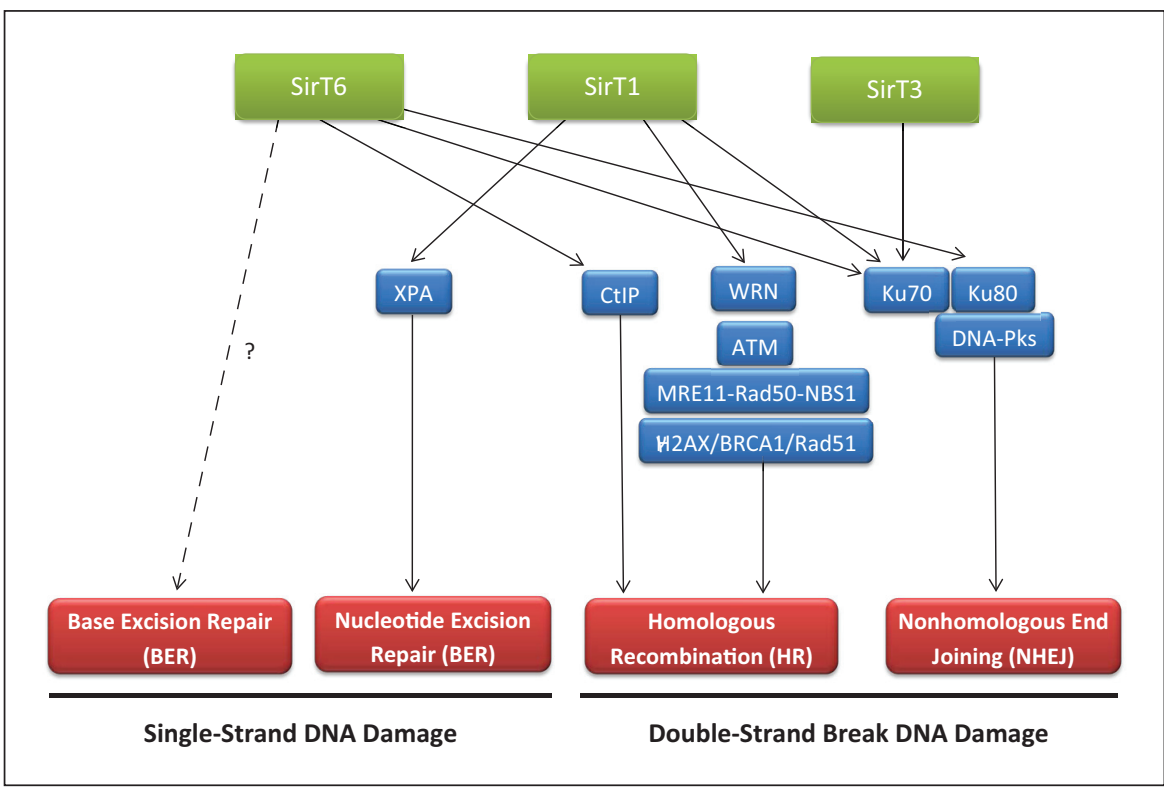

Figure 1. Sirtuins and DNA repair. Sirtuins are involved in DNA damage signaling and different DNA repair pathways (in red). The factors and pathways, through which they exert this function, are indicated. The link between SirT6 and BER has been established, although whether it is direct or not is still under discussion.

unchecked cell division. As we explain in the coming sections, sirtuins have developed an elaborate network of interactions and targets that are directly involved in cell growth, cell cycle progression, genome integrity, and cell death, which probably enables them to finely modulate cellular physiology under stress conditions.

\section{Sirtuins and Genome Stability}

Genomic instability features in the onset of most cancers. In fact, an unstable genome is a hallmark of nearly all solid tumors and adult-onset leukemias. ${ }^{18}$ The various factors that contribute to genome destabilization include different forms of stress, such as oxidative stress and genotoxic stress. Given their role in stress response, sirtuins are closely related to the regulation of chromatin dynamics in these compromising situations. Thus, they help stabilize the genome at two different levels: regulation of chromatin structure and expression and modulation of DNA repair (Figure 1).

\section{Sirtuins and Chromatin Regulation}

Despite having adopted various functions over the course of evolution, sirtuins have remained intimately connected to chromatin regulation through a functional link to the regulation of two histone posttranslational modifications that are crucial for chromatin structure and epigenetic phenomena: H4K16Ac and H3K9Ac. ${ }^{6}$ Among mammalian sirtuins, SirT1, 2, 6, and 7 have been shown to exert most of their function via chromatin regulation; the case of SirT3 is more complicated. However, only SirT1-3 and 6 help reguhistones and nonhistone proteins.

SirT1 function is the best characterized among the mammalian sirtuins. It is intimately linked to formation of both types of heterochromatin (facultative heterochromatin $[\mathrm{FH}]$ and constitutive heterochromatin $[\mathrm{CH}]$ ). SirT1 coordinates $\mathrm{FH}$ formation by deacetylating H4K16Ac, H3K9Ac, and H1K26Ac and by promoting $\mathrm{H} 3 \mathrm{~K} 9$ me 3 methylation through a close functional relationship with the histone methyltransferase Suv39h1, a keystone of chromatin organization. ${ }^{19-21}$ Suv39h1 methylates $\mathrm{H} 3 \mathrm{~K} 9 \mathrm{me}$, which is recognized by the heterochromatin structural protein HP1 through its chromodomain, establishing the basis of heterochromatin structure..$^{22}$ Formation of FH by SirT1 is crucial in late chromatin through deacetylation of cellular response to stress. A clear example is the inhibition of ribosomal gene expression upon oxidative stress. Under these conditions SirT1, Suv39h1, and nucleomethylin together induce $\mathrm{FH}$ formation in rDNA, silencing the expression of ribosomal genes and, consequently, decreasing the cellular production of proteins. ${ }^{23}$

Formation of FH by SirT1 is also important in the context of development in differentiation: SirT1 is part of PRC4, a complex that contains the polycomb H3K27me3 HMT Ezh2. This complex, which preferentially targets H1K26me3, seems to be involved in early development, in conditions of undifferentiation. This agrees with a general role for SirT1 in the inhibition of differentiation. ${ }^{24-27}$ Moreover, this might have important implications in cancer: first, because both SirT1 and Ezh2 protein levels are high in undifferentiated cells and decrease drastically upon differentiation and, second, because high levels of both factors correlate to cancer progression in a mouse model of prostate cancer. ${ }^{28}$

The interaction of SirT1 with $\mathrm{CH}$ is more complex, and evidence suggests that it occurs at two different levels. First, some authors have claimed that SirT1 may be present in both pericentromeric and telomeric regions of $\mathrm{CH}^{29,30}$ This would support a role for SirT1 in either the establishment or the maintenance of said regions. Indeed, loss of SirT1 has been associated with a loss of pericentromeric $\mathrm{CH}$ foci and desilencing of the $\gamma$-satellites in mice. ${ }^{31}$ Regarding telomeres, SirT1 was recently reported to contribute to genomic integrity via positive regulation of telomere length in vivo. ${ }^{30}$ SirT1 overexpression in mice decreases the rate of telomere erosion, whereas SirT1 deletion increases telomere shortening; the authors of the aforementioned study suggest that SirT1 overexpression affects the telomerase pathway. ${ }^{30}$ However, the levels of SirT1 in these regions remain unknown, particularly in the case of pericentromeric $\mathrm{CH}$ : although chromatin immunoprecipitation experiments have detected SirT1 in these regions, immunofluorescence studies do not indicate any local SirT1 enrichment 
and, moreover, do not reveal any localization. ${ }^{21}$ These seemingly contradictory results suggest that SirT1 levels are very limited, thereby challenging the view that SirT1 involvement is similar in pericentromeric and telomeric $\mathrm{CH}$ formation as in $\mathrm{FH}$ formation. Other evidence strongly suggests a direct role for SirT1 in $\mathrm{CH}$ formation and/or maintenance that would entail regulation of the available pool of nuclear Suv39h1. ${ }^{31}$ These studies have shown that the oxidative/metabolic stress response includes upregulation of Suv39h1 levels through a SirT1-dependent mechanism. SirT1 decreases Suv39h1 degradation by inhibiting Suv39h1 polyubiquitination by MDM2. This increase in Suv39h1 levels enhances Suv39h1 turnover in $\mathrm{CH}$, which in turn seems to accelerate renewal of the heterochromatin structure. This accelerated renewal correlates with greater genomic integrity during stress response. These observations reflect the first direct link between stress response and structural maintenance of $\mathrm{CH}$ and also support a view of chromatin as a dynamic entity under constant adaptation to environment. ${ }^{31}$

In contrast to the role of SirT1 as a genome protector, through the mechanisms we have explained above, other evidence suggests that SirT1 might actually cause the opposite effect. For example, Fraga et al. ${ }^{32}$ have described loss of global H4K16Ac and H4K20me3 as a hallmark in human tumors. Considering that SirT1 and SirT2 are the only sirtuins that seem to control global levels of H4K16Ac and that of these, only SirT1 seems to be upregulated in certain cancers, suggests that H4K16Ac loss in cancer may at least partially derive from SirT1 activity. Moreover, SirT1 is responsible for directly silencing certain tumor suppressor genes, and it has been detected in tumor suppressor promoter regions that correlate with hypoacetylation of $\mathrm{H} 4 \mathrm{~K} 16$ and $\mathrm{H} 3 \mathrm{~K} 9$ and to dense hypermethylation of $5^{\prime} \mathrm{CpG}$ islands. SirT1 inhibition leads to reexpression of these genes without affecting DNA methylation levels. ${ }^{33}$ Taken together, these observations suggest that the SirT1 overexpression described in some cancers could help silence tumor suppressor genes, which in turn would promote cancer development.

SirT6 was recently described to have histone deacetylase activity; since then, two of its targets have been identified: H3K9Ac and H3K56Ac. ${ }^{34-36}$ Evidence suggests that SirT6-mediated histone deacetylase activity promotes a specialized telomere chromatin structure required for genomic stability, ${ }^{18,37}$ which suggests that SirT6 plays an important role in cancer and aging. In addition, global hyperacetylation of its target $\mathrm{H} 3 \mathrm{~K} 56 \mathrm{Ac}$ has been described in various human cancers, including skin, thyroid, breast, liver, and colon cancers. Interestingly, loss of this modification correlates with tumor grade. ${ }^{38}$ This body of evidence suggests that SirT6 acts as a tumor suppressor by maintaining genome stability.

Another two sirtuins have been reported to participate in chromatin regulation: SirT2 and SirT3. SirT2, whose main role is in cell cycle regulation, regulates global levels of H4K16Ac. ${ }^{39}$ H4K16Ac deacetylation occurs specifically during the $\mathrm{G} 2 / \mathrm{M}$ transition, when SirT2 is shuttled to the nucleus, enabling chromatin compaction during metaphase. ${ }^{40}$ However, this process is not well understood; therefore, future work is required to elucidate the role of SirT2 in chromatin regulation and cell cycle control.

Although SirT3 is localized chiefly to the mitochondria, where it is apparently the main protein deacetylase, ${ }^{41}$ it also has a small nuclear population. This is consistent with its specificity for H4K16Ac and H3K9Ac as deacetylation substrates. ${ }^{42}$ However, unlike knockdown of SirT1 or SirT2, knockdown of SirT3 does not result in global H4K16 hyperacetylation, ${ }^{42}$ which suggests that SirT3 might be involved in the regulation of limited regions of the genome (i.e., a limited number of genes). However, more studies are required to determine the role of SirT3 in chromatin regulation.

\section{Sirtuins and DNA Repair}

DNA repair is essential for preserving the fidelity of genomic information. Sensing and removing damage generated by environmental events (e.g., stress or cell metabolism) or by the inevitable errors that arise during normal cell division is a critical challenge for all organisms, given that these phenomena are paramount in tumorigenesis. ${ }^{18}$ In hereditary cancers, genomic instability results from mutations in DNA repair genes, whereas in sporadic (nonhereditary) cancers, the molecular basis of genomic instability remains unclear. SirT1 was recently reported as playing an important role in DNA repair and in maintaining genome stability: specifically, $\mathrm{SirT}^{-/}$embryos showed more chromosomal aberrations and impaired DNA repair than did wildtype (WT) embryos. ${ }^{16}$ As we described above, in yeast, one of the main functions of Sir $2 p$ is to silence the mating-type loci HML and HMR. ${ }^{2}$ However, during DNA damage, the Sir $2 p$ complex dissociates from HM loci and relocalizes to sites of DNA breakage, ${ }^{43-46}$ which results in transient expression of genes related to DNA repair in HM loci as well as in chromatin remodeling around DNA break sites to facilitate recruitment of repair factors. ${ }^{47,48}$ Recruitment of SirT1 to double-strand breaks (DSBs) is similar to that of yeast Sir2p and, together with other histonemodifying enzymes, induces epigenetic changes around the break site that result in chromatin remodeling. ${ }^{48,49}$ At DSBs, SirT1 may deacetylate histones and/or DNA repair factors. SirT1 is important for modulating $\gamma$-H2AX, BRCA1, Rad51, and NBS1 foci formation upon $\gamma$-irradiation, through direct recruitment of these proteins to the DNA damage site. ${ }^{16}$ Accordingly, SirT1 directly interacts with and deacetylates NBS1, a checkpoint factor that is involved in detection and activation of DNA repair and that is part of the DNA damage sensor complex MRN (MRE11-RAD50NBS1).$^{50}$ In related work, Oberdoerffer et $a l^{29}$ showed that the relocalization of SirT1 to DSBs depends on ATM-mediated signaling through $\mathrm{H} 2 \mathrm{AX}$ phosphorylation, which parallels the situation in yeast, whereby recruitment of Sir2p to DSBs requires DNA damage signaling via MEC1, the ATM ortholog. Other groups have reported that SirT1 regulates 
repair of certain DSB events independently of the signaling kinase pathway. ${ }^{51}$ In particular, SirT1 is involved in homologous recombination (HR) through a Rad51-independent mechanism that involves the WRN helicase. ${ }^{51}$ This functional relationship between SirT1 and WRN is supported by previous studies that reported that deacetylation of WRN by SirT1 increases WRN activity and function in DNA repair. ${ }^{52}$ Corroborating a role for SirT1 in HR, SirT1-tg mice, which contain an extra copy of the SirT1 gene, exhibit higher frequencies of sister chromatid HR events at telomeres, centromeres, and chromosomes arms, thereby indicating that SirT1 overexpression may affect DNA repair efficiency. ${ }^{30}$

Another interesting link between SirT1 and DNA repair is Ku70, which is involved in DNA repair of DSBs by nonhomologous end joining (NHEJ). ${ }^{53} \mathrm{Ku} 70$ is mainly located in the nucleus, where it participates in DNA repair, and a small fraction is located in the cytoplasm, where it regulates apoptosis. In response to DNA damage, Ku70 is acetylated at multiples lysines, which results in a $\mathrm{Ku} 70$-BAX dissociation that permits translocation of BAX to the mitochondria to promote apoptosis. Deacetylation of Ku70 by SirT1 blocks the conformational change in BAX and its translocation to the mitochondria, consequently inhibiting mitochondrial apoptosis and inducing Ku70-dependent DNA repair. ${ }^{54,55}$ Apart from SirT1, SirT3 has also been described as promoting cell survival through $\mathrm{Ku} 70$ deacetylation in response to genotoxic agents, suggesting that SirT3 also could be involved in Ku70-dependent DNA repair signaling. ${ }^{56}$

SirT1 is also involved in repairing damaged single-strand DNA. It has been imputed in UV-induced DNA repair through the nucleotide excision repair (NER) pathway. UV irradiation stimulates the xeroderma pigmentosum group A (XPA) protein, a NER core factor, which interacts with SirT1 and leads to decreased levels of acetylated XPA, ${ }^{57}$ which is required for optimal NER pathway function.
Among the remaining sirtuins, SirT6 is also important in DNA repair. Loss of SirT6 in mice correlates with accumulated mutations and decreased genomic stability. SirT $6^{-/-}$mouse embryonic fibroblasts (MEFs) and $\mathrm{SirT6}^{-1-}$ mouse embryonic stem cells (mESCs) are associated with a reduced proliferative rate and DNA damage hypersensitivity, as well as harbor multiple chromosomal defects, including fragmentation, detached centromeres, gaps, and translocations. ${ }^{14,17}$ SirT6 was initially thought to play a role in base excision repair (BER) for two main reasons: first, hypersensitivity of SirT6 $^{-/}$cells to DNA damage has been remedied by overexpression of the isolated dRP lyase domain of DNA polymerase $\beta$, which catalyzes the rate-limiting step in $\mathrm{BER}^{17}$; second, BER and maintenance of genomic stability require that the deacetylase domain of SirT6 be intact. ${ }^{17}$ However, the role of SirT6 in BER has not been unequivocally demonstrated: in DNA damage experiments, SirT6 has not been found to physically interact with BER factors or to co-localize with these factors at the damage sites. ${ }^{17,37}$ Recent biochemical and functional studies of SirT6 in human cells have revealed that SirT6 helps enable efficient DNA DSB repair. ${ }^{58}$ Furthermore, SirT6 has been reported to interact with proteins involved in the NHEJ pathway of DSB repair, including DNA-PKcs and $\mathrm{Ku} 70 / 80{ }^{58}$ Consistent with this finding, SirT6 has been shown to dynamically associate with chromatin in response to DSBs, promote a global decrease in H3K9Ac levels following DNA damage, and stabilize the DNA damage-dependent association of DNAPKes with chromatin. This suggests that SirT6 is required for changes in chromatin structure at DSBs that enable efficient recruitment of DSB repair proteins. Kaidi et $a l^{59}$ recently reported that, in addition to its function in DNA repair, SirT6 also promotes DNA end resection - a crucial step in DSB repair by HR - by binding to and deacetylating CtIP (C-terminal binding protein interacting protein).
This body of evidence suggests that SirT1, SirT6, and possibly SirT3 have important and diverse roles in DNA repair and supports a role for each as a tumor suppressor via their respective functions in repairing DNA damage, maintaining genome integrity, and inhibiting tumorigenesis ${ }^{60}$ (Figure 1).

\section{Sirtuins and Stress Response}

Throughout evolution, from early eukaryotes onwards, sirtuins have helped organisms adapt to oxidative, metabolic, or genotoxic stress by activating the stress response pathway through various factors, controlling chromatin integrity and expression, signaling DNA damage and repair, and modulating cell metabolism. However, sirtuins are not always committed to cell survival: under certain extreme conditions, such as chronic stress, SirT1, SirT2, and SirT3 can protect the organism by inducing cell senescence or apoptosis $^{61-63}$ (Figure 2). Herein lies what may be a cornerstone for understanding the contradictory nature of sirtuins in cancer. SirT1 best illustrates this contradiction: whereas its overexpression inhibits oncogene-induced senescence ${ }^{64}$ and its inhibition by Sirtinol results in a senescence-like cell growth arrest with attenuated Ras-MAPK signaling in human cancer cells, ${ }^{65,66} \mathrm{SirT}^{-/}$MEFs are more resistant to senescence than are WT MEFs. ${ }^{61}$

SirT1 has been linked to stress response through its regulation of many important factors in cancer. Among the most important of these is p53, which is critical for cell cycle checkpoint regulation, apoptosis, and tumor suppression. ${ }^{67,68}$ In addition, more than half of all human cancers are related to p53 mutations, and a strong body of evidence suggests that cancers in which p53 is not mutated exhibit some alteration in its pathway. ${ }^{69-71}$ SirT1 apparently regulates both types of known p53-mediated apoptosis (p53-transcriptional dependent and p53-transcriptional independent). SirT1 regulates p53 in various ways - chiefly, via deacetylation of $\mathrm{p} 53$, which induces 


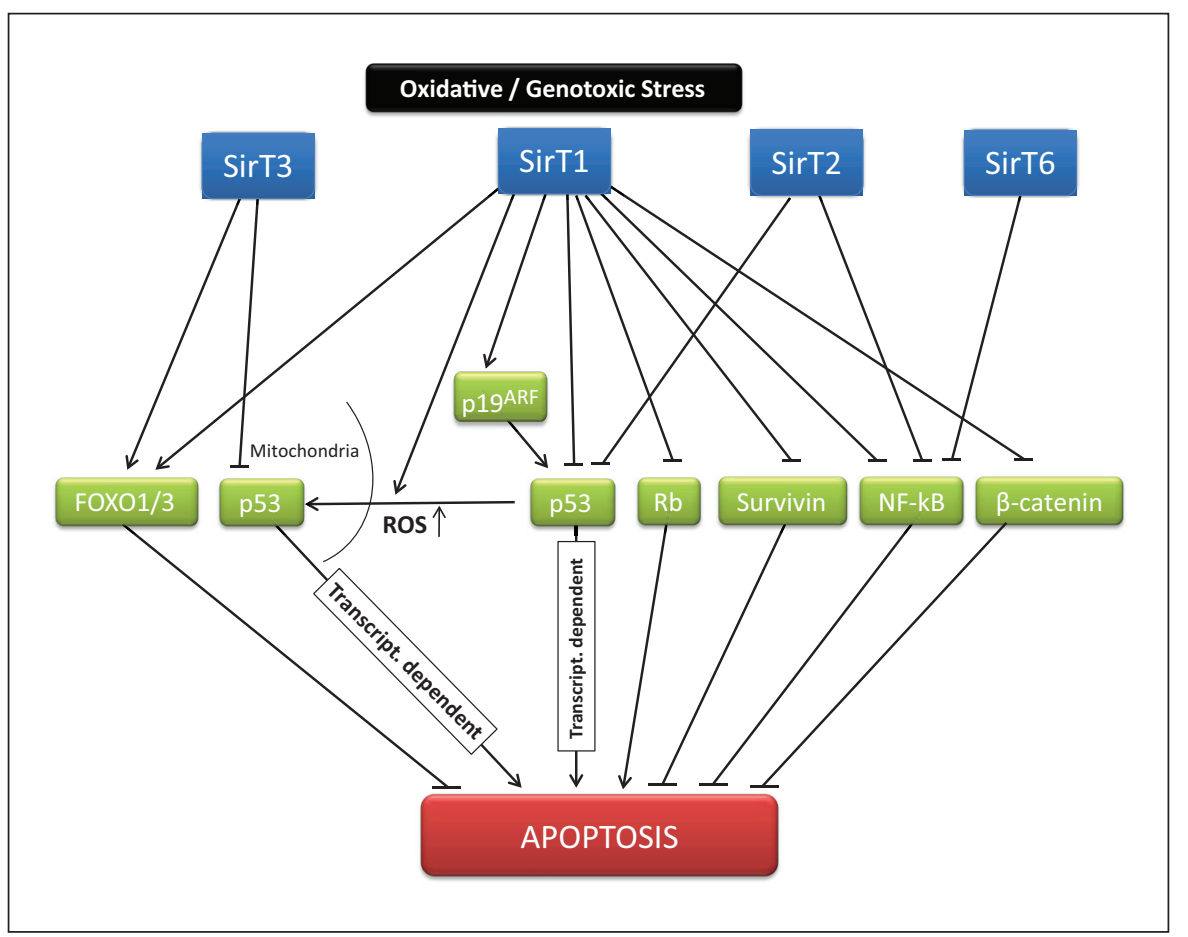

Figure 2. Sirtuins and cell survival. Under different forms of stress, sirtuins control cell fate through, among other mechanisms, modulation of apoptosis. The decision process before a particular situation is based as a result on a complex net of interactions and targets established by different sirtuins. The main described mediators and pathways of this sirtuin-dependent signaling are indicated.

inactivation of $\mathrm{p} 53$ and associates with inhibition of p53-dependent apoptosis. ${ }^{67,68}$ Accordingly, SirT1 ${ }^{-/-}$mice exhibit lower levels and hyperacetylation of $\mathrm{p} 53$ and higher levels of radiation-induced apoptosis than do WT mice. ${ }^{72}$ This observation has led researchers to hypothesize that SirT1 activity may elevate cancer risk in mammals by inhibiting p53induced apoptosis. ${ }^{73-76}$ However, other evidence suggests that SirT1 could regulate p53 in a more complex fashion. For instance, SirT1 could drive activation of p53 via regulation of $\mathrm{p} 19^{\mathrm{ARF}}$. In fact, $\mathrm{SirT}^{-/-}$MEFs show lower levels of the tumor suppressor p19 $9^{\mathrm{ARF}}$, which positively regulates $\mathrm{p} 53 .{ }^{61} \mathrm{p} 19^{\mathrm{ARF}}$ does not appear to be acetylated, and despite the lack of understanding of how SirT1 regulates expression of $\mathrm{p} 19^{\mathrm{ARF}}$, this regulation appears to have major implications for how SirT1 regulates senescence through p53. ${ }^{61}$ Thus, SirT1 seems to limit clearly affect p53-dependent functions, and none of the observed phenotypes in $\mathrm{SirT}^{-/-}$background, which include hypersensitivity to radiation and apoptosis, seem to depend on p53 activity. ${ }^{78}$ This contradiction between in vivo data and in vitro data may stem from functional redundancy among sirtuins. At least two other sirtuins have been shown to regulate p53: SirT2 and SirT3. SirT2 not only functions as a mitotic checkpoint in response to mitotic stress but also regulates cell death in response to certain conditions of DNA damageinduced stress. ${ }^{79,80}$ Matsushita et al. ${ }^{79}$ observed that, compared to WT DT40 cells, SirT1- and SirT2-deficient DT40 cells exhibited significantly greater reporter activation by $\mathrm{p} 53$ and its related factor $\mathrm{p} 73$ in response to ionizing radiation. This suggests that SirT2 could downregulate p53 and p73 activity in response to DNA damage. Consistently, recent work suggests that downregulation of SirT2 causes apoptosis in cancer cell lines such as HeLa, but not in normal cells, through accumulation of p53, which results from p38 MAPK activation-dependent degradation of p300 and subsequent MDM2 degradation. ${ }^{80}$ In the case of SirT3, recent reports suggest that it acts as a protein regulator of p53-induced senescence. ${ }^{81}$ As we mentioned earlier, $\mathrm{p} 53$ executes some of its antiproliferative functions in the mitochondria. ${ }^{82}$ SirT3 partially abrogates p53 activity to promote growth arrest and senescence. This inhibitory effect of SirT3 over p53 is blocked by interaction of $\mathrm{p} 53$ with BAG-2, a component of the CHIP ubiquitin ligase complex. ${ }^{81}$ The researchers discovered a network in which sirtuins and p53 cochaperones may coordinate cellular fate independently of transcriptional activity.

Other key players in the stress response regulated by sirtuins are the forkhead-box (FOXO) family of transcription factors, which are very important in both stress response and cancer because of their roles in cell cycle arrest, DNA repair, and apoptosis. ${ }^{83-86}$ FOXO proteins are tumor suppressors, and they 
were recently found as fusion proteins following chromosomal translocations in various cancers. ${ }^{87-93}$ In response to oxidative or genotoxic stress, FOXO proteins translocate from the cytoplasm to the nucleus, where they activate myriad genes involved in cell cycle arrest, DNA repair, and apoptosis. ${ }^{94-96}$ Acetylation of FOXO reduces its binding to DNA and enhances its phosphorylation and inactivation. ${ }^{97}$ SirT1 deacetylates FOXO proteins, promoting transcription of FOXO targets involved in stress resistance and a decrease in transcription of apoptosisrelated genes. ${ }^{94,96,98}$ For instance, FOXO3 deacetylation by SirT1 inhibits FOXO3's ability to induce apoptosis after cellular stress and enhances its ability to induce cell cycle arrest; in contrast, in SirT1 $1^{-/}$ cells, FOXO3's ability to induce cell cycle arrest is diminished. ${ }^{94}$ Moreover, SirT1 promotes survival after oxidative stress by inducing DNA repair in cooperation with FOXO1. SirT1 and FOXO1 are recruited to the manganese superoxide dismutase promoter, and SirT1 activity is required for transactivation of the antioxidant enzyme. ${ }^{99}$ Supporting these findings, SirT1-dependent deacetylation of FOXO1 represses its transcriptional and pro-apoptotic activity in prostate cancer cells. ${ }^{100}$ As in the case of p53, other sirtuins are also involved in FOXO activity regulation. In fact, SirT2 is the main deacetylase of cytosolic FOXO1. In response to stress, FOXO1 dissociates from SirT2 and is subsequently acetylated. The acetylated FOXO1 can then form a complex with Atg7, which in turn is critical for induction of autophagy, a process that has also been associated with inhibition of tumor development. ${ }^{101-104}$ In addition, Jacobs et al.$^{105}$ have suggested that FOXO3a is also a mitochondrial protein and that its mitochondrial function may be regulated by interaction with SirT3. In fact, they showed that SirT3 overexpression increases both the DNAbinding ability of FOXO3a and FOXO3adependent gene expression.

To further complicate this scenario, FOXO proteins and p53 share many transcriptional targets, and a report that
FOXO proteins and p53 interact after oxidative stress suggests that SirT1 might regulate survival through both p53 and FOXO proteins. ${ }^{94}$ In cells containing WT p53, FOXO proteins, and intact cell cycle checkpoints under normal conditions (i.e., no stress), SirT1 limits tumor formation by inducing cell senescence. In contrast, in conditions of DNA damage-inducing stress, SirT1 induces cell cycle arrest and DNA repair rather than apoptosis. However, loss of p53 and other tumor suppressors could result in increased SirT1 expression, which in turn could contribute to tumor formation; this is probably the reason that SirT1 depletion inhibits growth of certain tumors. ${ }^{66,106}$ Thus, further research is required to elucidate the complex functional relationship between sirtuins, p53, and FOXO proteins in tumor cells. ${ }^{3}$

Another interesting link of sirtuins to stress is the transcriptional factor NF- $\mathrm{KB}$ (nuclear factor- $\mathrm{\kappa B}$ ). NF- $\mathrm{\kappa B}$ plays a pivotal role in regulating gene expression programs related to aging, proliferation, and inflammation. ${ }^{107,108}$ SirT1 interacts with and deacetylates NF- $\mathrm{BB}$, modulating its DNA binding and transcriptional activity. ${ }^{109-111}$ Treatment of cells with the SirT1 activator resveratrol correlates with a loss of NF- $\kappa B$-regulated gene expression and sensitization of the cells to tumor necrosis factor $\alpha(\mathrm{TNF} \alpha)$ induced apoptosis; these findings suggest that SirT1 activity augments apoptosis in response to TNF $\alpha$ via NF- $\kappa B$ inhibition. ${ }^{109}$ Functioning of the $\mathrm{NF}-\kappa \mathrm{B}$ family members is also apparently regulated by SirT2 and SirT6. SirT2 has been reported to interact with p65 (an NF- $\mathrm{BB}$ family member) in the cytoplasm and to deacetylate p65 at K310 after TNF $\alpha$ stimulation. ${ }^{112}$ Moreover, in SirT2 ${ }^{-/-}$MEFs, p65 is hyperacetylated at K310, which correlates with an increase in Mpa2l gene expression. These data suggest that SirT2 deacetylases NF- $\mathrm{KB}$ and is an important regulator of $\mathrm{TNF} \alpha$-induced $\mathrm{NF}-\mathrm{\kappa B}$ dependent gene expression. ${ }^{112}$ SirT6 also plays a key role in transcriptional regulation via NF- $\mathrm{kB}$. Following activation of NF- $\kappa B$ by $T N F \alpha$, SirT6 is recruited to promoters of a subset of $\mathrm{NF}-\kappa \mathrm{B}$ target genes through a physical interaction with the NF- $\mathrm{KB}$ subunit RELA (p65). ${ }^{113}$ At these promoters, SirT6 deacetylates H3K9Ac and destabilizes RELA-promoter interaction, thereby attenuating NF- $\kappa \mathrm{B}$ signaling. Accordingly, SirT6-deficient human and mouse cells, as well as multiple types of SirT6-deficient mouse tissue, are associated with hyperactivation of certain $\mathrm{NF}-\mathrm{\kappa B}-$ dependent gene expression programs. ${ }^{113}$ In addition, Kawahara et al. ${ }^{113}$ reported that RELA heterozygosity partially rescues the premature lethality of SirT6 $6^{-1-}$ mice, attenuates some of their degenerative and metabolic defects, and reverses the excessive levels of NF- $\mathrm{KB}$ driven gene expression observed. Recently, SirT6 was discovered to facilitate transcriptional regulation through HIF $1 \alpha$, a transcription factor important in cancer cell metabolism and cellular response to hypoxia. ${ }^{14,115}$ SirT6 was shown to interact with HIF $1 \alpha$ and to associate with the promoters of a subset of glucose-regulatory HIF $1 \alpha$ target genes in an HIF1 $\alpha$-dependent manner. ${ }^{116}$ Accordingly, SirT6 ${ }^{-/}$mice show H3K9 hyperacetylation at these promoters and increased gene expression, which leads to increased glucose uptake and glycolysis in several tissues. ${ }^{116}$ These data suggest that under normal nutrient conditions, SirT6 might compete with HIF1 $\alpha$ to direct glucose flux away from glycolysis and toward oxidative phosphorylation, probably by inhibiting HIF $1 \alpha-$ promoter association or by blocking HIF $1 \alpha$ activity at its target genes. ${ }^{37}$ The newly discovered roles for SirT6 as a transcriptional regulator suggest that modulation of NF-KB and HIF $1 \alpha$ gene expression programs might be only the tip of the SirT6 iceberg, given that hundreds of genes are differentially expressed in $\mathrm{SirT6}^{-1-}$ mouse cells compared with WT controls. ${ }^{37,113}$

Finally, we would like to underscore the central role of mitochondria in aging and carcinogenesis. Mitochondria are 
the principal site for production of the ROS that cause oxidative stress. ${ }^{117}$ On the basis of proteomics results, researchers have recently suggested that $20 \%$ of mitochondrial proteins are acetylatedchiefly, those involved in life span and metabolism. ${ }^{118}$ This suggests that mitochondrial sirtuins could play an important role in the altered energy metabolism and response to oxidative stress described in tumor cells. ${ }^{3}$ Under stress conditions, such as DNA damage induced by etoposide and UV irradiation, the nuclear SirT3 population translocates to the mitochondria. ${ }^{41,42,119,120}$ Some reports have shown that SirT3 acts as a mitochondrial tumor suppressor. ${ }^{121}$ Thus, SirT3 $^{-/-}$MEFs present abnormal mitochondrial physiology and increased stress-induced superoxide levels and genomic instability. Corroborating a role for SirT3 as a tumor suppressor, SirT3 ${ }^{-/-}$MEFs infected with a single oncogene become immortalized and transformed. Furthermore, some human cancer specimens (e.g., some types of breast cancer) exhibit abnormally low SirT3 levels, and SirT3 ${ }^{-/}$mice develop estrogen receptor (ER)/progesterone receptor (PR)-positive mammary tumors. ${ }^{121}$ Last, superoxide dismutase expression prevents this transformation and reverses both the tumorpermissive phenotype and the stressinduced genomic instability.

\section{Pathways of Sirtuin Regulation in Cancer}

Sirtuins have also been functionally linked to cancer-related pathways other than those described above. For example, SirT1 is functionally linked to the regulation of the tumor suppressor retinoblastoma $(\mathrm{Rb})$, a nuclear protein that regulates the $\mathrm{G}_{1} / \mathrm{S}$ transition by interacting with the E2F transcription factors. ${ }^{122}$ The activity of $\mathrm{Rb}$ is regulated by phosphorylation and acetylation at multiple residues. Deacetylation of Rb by SirT1 inhibits Rb-dependent apoptosis. SirT1 and $\mathrm{Rb}$ form a complex in which the pocket domain of $\mathrm{Rb}$ undergoes SirT1dependent deacetylation, resulting in apoptosis regulation. ${ }^{123}$
Another link of sirtuins to cancer is their functional relationship to the $\beta$-catenin pathway and, consequently, to WNT signaling. $\beta$-Catenin is the principal effector in the WNT signaling pathway, which controls the maintenance, development, and carcinogenesis of stem cells. ${ }^{124}$ Constitutive activation of the $\beta$-catenin pathway has been found in $90 \%$ of colorectal cancers, and alteration of this pathway has been reported in many other cancers, such as breast and ovary cancers and melanoma. ${ }^{125,126}$ Two recent studies have associated increased WNT signaling to accelerated aging and have stated that calorie restriction (CR) attenuates this phenotype. ${ }^{127,128}$ Interestingly, sirtuin function has been linked to the health benefits of CR. CR induces a 2-fold increase of SirT1 expression in the intestine of rodents, which significantly reduced tumor formation, proliferation, and animal morbidity in APC $^{\min /+}$ mice. ${ }^{129}$ SirT1 deacetylates $\beta$-catenin, which suppresses localization of $\beta$-catenin to the nucleus and reduces the ability of $\beta$-catenin to activate transcription, suggesting that SirT1 functions as a tumor suppressor. ${ }^{129}$

Another important role for SirT1 in cancer is its suppression of the apoptosis inhibitor Survivin in breast cancers associated with the tumor suppressor BRCA1, which is particularly relevant to breast and ovarian cancers and is involved in many different pathways, including genome stability protection, cell cycle control, and apoptosis. Survivin is overexpressed in cancers. In fact, BRCA1-associated breast cancers show abnormally low levels of SirT1 and high levels of Survivin. In normal cells, BRCA1 is located at the SirT1 promoter, where it increases expression of SirT1,${ }^{130}$ which goes on to inhibit Survivin expression by deacetylating histone $\mathrm{H} 3$ in nucleosomes at the Survivin promoter. ${ }^{130}$

The oncogene B cell lymphoma 6 protein (BCL6) is another interesting SirT1 target. It is a transcriptional factor expressed in mature B cells that is required for formation of germinal centers, through repression of genes involved in differentiation and apoptosis. ${ }^{131}$ BCL6 is involved in the pathogenesis of diffuse large-cell lymphoma and Burkitt lymphoma. ${ }^{131,132}$ Different studies have suggested that SirT1 binds to and deacetylates BCL6, thereby decreasing the oncogene's activity. ${ }^{67,132}$

\section{Modulation of Sirtuins in Cancer}

Expression of various sirtuins is altered in many types of cancer. For example, SirT1, 4, and 7 have been described as being upregulated in certain cancers, ${ }^{60,133-136}$ whereas SirT2 is downregulated in gliomas and gastric carcinoma, ${ }^{137,138}$ as well as in melanomas, in which a mutation in the catalytic domain of SirT2 (P199L) that eliminates its enzymatic activity has been described. ${ }^{139}$ Evidence suggests that SirT2 acts as a tumor suppressor and that its loss compromises the mitotic checkpoint, contributing to genomic instability and tumorigenesis. ${ }^{137,140,141}$ The case of SirT3 is more complex since it has been found to be upregulated or downregulated in different types of breast cancer. ${ }^{121,136}$ However, SirT5 and SirT6 levels are not known to be altered in cancer.

The mechanisms through which these sirtuins seem to be upregulated are quite diverse. Regulation of SirT1 expression in cancer is perhaps the most interesting case, as it involves multiple factors that are highly relevant to cancer. The reasons for SirT1 overexpression in cancer are unknown, and whether this overexpression actually causes tumorigenesis or is simply a consequence thereof remains uknown. ${ }^{60,76,133-135}$

SirT1 overexpression partly occurs at the transcriptional level, following loss of SirT1 promoter repressors. Among the best characterized of these factors is the tumor suppressor hypermethylated in cancer 1 (HIC1). ${ }^{142}$ Both SirT1 mRNA and protein levels are abnormally high in $\mathrm{HICl}^{-1-} \mathrm{MEF}$ cells. Accordingly, hypermethylation of the $\mathrm{HIC} 1$ promoter, which has been described in certain cases of tumor formation, results in SirT1 upregulation. $^{72,73,143,144} \mathrm{HIC1}$ forms a transcriptional repression complex with SirT1 that, upon binding to the SirT1 promoter, 
inhibits SirT1 expression. ${ }^{73}$ Accordingly, SirT1 is downregulated during aging, and cells lacking $\mathrm{HIC} 1$ do not exhibit this regulation, making them resistant to replicative senescence after oxidative stress and vulnerable to transformation if mutations are propagated. In addition, $\mathrm{HIC}^{+/-}$ mice are tumor prone and show a p53- and SirT1-dependent block in apoptosis induction in response to DNA damage. ${ }^{73,144}$

Interestingly, a common feature of SirT1 regulation is that SirT1 apparently establishes a feedback loop with most of the factors that regulate its expression. SirT1 interacts with and deacetylates $\mathrm{HIC} 1$, thereby repressing its expression and regulating the activity of $\mathrm{HIC} 1{ }^{73,145}$ Another example is the transcription factor Aiolos, a member of the Ikaros family that is involved in B cell differentiation. Aiolos negatively regulates SirT1 expression, and its loss, which is associated with lymphoma development, leads to SirT1 upregulation. ${ }^{146}$

Another major regulatory factor in SirT1 expression is p53. As we mentioned above, SirT1 also regulates p53 activity, suggesting the existence of a regulatory feedback loop between these two proteins. Nemoto et al. ${ }^{147}$ described two p53 binding sites in the SirT1 promoter that normally repress SirT1 expression. This could explain the SirT1 overexpression observed in tumors that have lost p53. Interestingly, a newly discovered alternative isoform of SirT1, SirT1- $\Delta$ Exon 8 , and an autoregulatory loop between this isoform and p53 have recently been described. ${ }^{148}$ SirT1 is alternatively spliced in a manner that is stress sensitive, p53 dependent, and conserved in mammals. SirT1 and SirT1$\Delta$ Exon8 differ in terms of stress sensitivity, RNA and protein stability, protein-protein interactions, and deacetylase activity. This new evidence suggests that the ability of SirT1 to regulate mammalian biology at different levels could be partially explained by the existence of alternate isoforms of SirT1. ${ }^{148}$

In addition and related to p53-dependent SirT1 regulation, another (positive) feedback loop has recently been described between miR-34, p53, and SirT1. MicroRNAs (miRNAs) are small noncoding RNAs that inhibit target protein expression by posttranscriptional repression. ${ }^{149,150}$ They are essential in the development, physiology, and pathology of animals and plants and have been recently linked to tumorigenesis, tumor progression, and metastasis. ${ }^{151-155} \mathrm{p} 53$ regulates the expression of the miR-34 family of miRNAs, which are involved in modulating cell cycle progression, senescence, and apoptosis. ${ }^{156-162}$ Interestingly, the $3^{\prime}$ UTR of the SirT1 transcript contains a miR-34a-responsive element. Overexpression of miRNA34a due to 553 activity leads to a decrease in SirT1 protein levels, via posttranslational inhibition, and to a concomitant increase in p53 acetylation and p53-dependent apoptosis. ${ }^{161}$ Furthermore, researchers have also found that the miR-34a/SirT1 cascade significantly contributes to chemoresistance in PC3 human prostate cancer cellsnamely, ectopic miR-34a expression attenuates chemoresistance to camptothecin by inducing apoptosis. ${ }^{163,164}$ Likewise, Akao et al. ${ }^{165}$ found that miR-34a expression was significantly downregulated in DLD-1/5FU (5-fluorouracilresistant DLD-1) cells compared with the parent DLD-1 cells both under steady-state conditions and after 5-FU treatment. Introducing miR-34 into DLD/5FU cells significantly attenuates their resistance to 5-FU, which leads to a reduction in expression of SirT1 and the E2F proteins. This in turn suggests that the miR-34/SirT1/E2F cascade significantly contributes to resistance of DLD-1 cells to 5-FU. ${ }^{165}$

Other regulatory feedback loops between SirT1 and different key players in cancer have been reported. These include a positive feedback loop between SirT1 and FOXO1, ${ }^{166}$ whereby FOXO1 may regulate SirT1 expression by binding to the SirT1 promoter region. ${ }^{166} \mathrm{~A}$ regulatory loop between SirT1 and the transcription factor E2F1, a tumor suppressor, and cell cycle and the apoptosis regulator has also been discovered. Under cellular stress or DNA damage, E2F1 binds to the SirT1 promoter and induces its expression. ${ }^{167}$ E2F1 is acetylated by p300/CBP-associated factor (PCAF), which enhances E2F1 transcriptional activity. ${ }^{168}$ SirT1 also deacetylates E2F1 and inhibits E2F1-induced transcription of target genes, including SirT1 itself; this may regulate induction of apoptosis in response to DNA damage. ${ }^{167}$

Another interesting example is the recently described negative feedback loop between SirT1 and the oncogene c-Myc, which supports a tumor suppressor role for SirT1 $1{ }^{169} \mathrm{c}$-Myc binds to the SirT1 promoter and induces expression of SirT1, which in turn deacetylates $\mathrm{c}-\mathrm{Myc}$ and negatively regulates $\mathrm{c}-\mathrm{Myc}$ activity, consequently reducing c-Myc target gene expression and cellular transformation. ${ }^{169}$ The authors of that study suggest that SirT1 blocks tumor initiation in premalignant cells by inhibiting c-Myc. ${ }^{169}$

Another mechanism driving upregulation of SirT1 is stabilization of its mRNA mediated by HuR, a ubiquitous oncogenic RNA-binding protein that binds to 3'UTR of the SirT1 transcript. ${ }^{170}$ HuR levels decrease dramatically as cells age and reach senescence, ultimately destabilizing SirT1 mRNA. ${ }^{170,171}$ Following oxidative damage, HuR is phosphorylated by the tumor suppressor Chk2, causing it to dissociate from SirT1 mRNA. The decrease in SirT1 levels makes cells more sensitive to apoptosis induction. ${ }^{170}$ This is yet another mechanism in the fine balance between DNA repair and senescence: high levels of DNA damage and increased activation of Chk2 could decrease expression of SirT1, thereby shifting the balance toward apoptosis.

As we mentioned earlier, SirT1 is part of the complex PRC4. ${ }^{28}$ Overexpression of PRC4 components such as EZH2, Suz12, Eed, and SirT1 has been reported in many cancer tissue types. ${ }^{28,172,173}$ Interestingly, overexpression of $\mathrm{EZH} 2$ results in overexpression of all the other PRC4 components 
through a currently unknown mechanism. ${ }^{28}$ Furthermore, in stem cells, SirT1 has been directly associated with Suz12, and in breast and colon cancers, SirT1 is overexpressed, as are PcG proteins. ${ }^{28}$

Apart from regulation of SirT1 expression, cancer and cell fate may also be linked to modulation of SirT1 activity. For example, SirT1 activity could be modulated by AROS (active regulator of SirT1), the tumor suppressor DBC1 (deleted in breast cancer 1), and the proapoptotic nuclear desumoylase SENP1. AROS enhances the activity of SirT1 by directly binding to its N-terminus, consequently inhibiting p53-mediated transcriptional activity. ${ }^{174}$ In contrast, SENP1 desumoylates and inactivates SirT1 by binding to its C-terminus, thereby increasing p53 activity. $\mathrm{DBC} 1$, which is homozygously deleted in some breast cancer patients, inhibits SirT1 activity by directly binding to its catalytic domain. ${ }^{75}$ Depleting DBC1 increases SirT1-mediated p53 deacetylation and inhibits p53-mediated apoptosis. ${ }^{74,75}$ Moreover, a recent study suggests that $\mathrm{DBC} 1$ disrupts the Suv39h1-SirT1 complex and inactivates both enzymes, thereby implying that DBC1 could help modulate SirT1 functioning in genome stability. ${ }^{175}$ In contrast, recent DNA microarray data sets have detected overexpression of DBC1 in breast cancer. ${ }^{176}$ In addition, DBC1 has been imputed in the modulation of ER- $\alpha$ and described as being a coactivator of androgen receptor (AR), suggesting that it may play a role in cancer cell survival. ${ }^{177,178}$ Furthermore, 2 recent studies suggest that the balance between DBC1 and SirT1 expression is lost in breast cancer and that this loss is associated with a poor prognosis for patients. ${ }^{179,180}$

Nicotinamide phosphoribosyltransferase (NAMPT) is yet another important enzymatic regulator of SirT1. It indirectly controls SirT1 activity by regulating $\mathrm{NAD}^{+}$levels. Induction of NAMPT following certain forms of stress leads to an increase in $\mathrm{NAD}^{+}{ }^{181}$ This increase induces SirT1 activity, which triggers changes in gene expression that parallel those in cells that

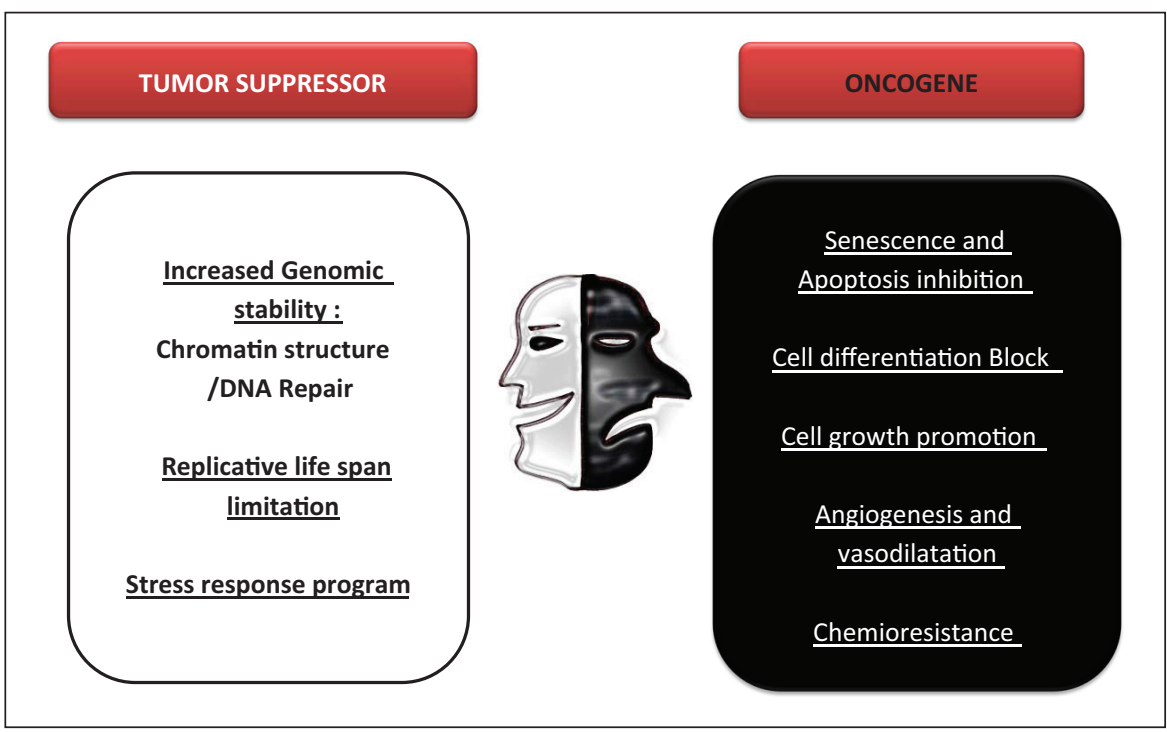

Figure 3. SirT1 as a tumor suppressor or/and tumor promoter. The evidence reported supports both an oncogenic and a tumor suppressor role for SirT1. Here, we indicate the different functions described for SirT1 that support one role or the other.

Overexpress SirT1. ${ }^{182}$ Inhibition of NAMPT induces premature senescence, whereas overexpression of NAMPT delays senescence and increases survival after oxidative stress in a SirT1dependent manner. ${ }^{183}$ NAMPT was very recently shown to be overexpressed in numerous human cancer cells along with SirT1. ${ }^{184}$ In addition, $\mathrm{NAD}^{+}$has been found to bind to tetrameric p53, consequently altering the conformation of p53 and preventing its binding to DNA. ${ }^{185}$ Contrary to NAMPT function, activation of poly(ADP-ribose) polymerase (PARP) 1 after DNA damage depletes $\mathrm{NAD}^{+}$and increases nicotinamide levels, consequently inhibiting sirtuin activity. ${ }^{186}$

Surprisingly, a recent report indicates that although SirT1 is mainly located in the nucleus in primary cells, its primary localization in cancer/transformed cells (e.g., prostate cancer cell lines, lung and breast cancer cells, transformed cell lines, and prostate carcinoma tissue) is the cytoplasm. ${ }^{187}$ As we mentioned earlier, localization is paramount in regulating sirtuin function. Byles et al. ${ }^{187}$ suggest that this aberrant cytoplasm localization is one of the specific alterations of SirT1 in cancer cells and derives from greater cytoplasmic stabilization of SirT1 enabled by the PI3K/IGF-1R signaling pathway.

\section{Sirtuins in Cancer: Tumor Suppressors, Oncogenic Factors, or Both?}

The roles of sirtuins in cancer remain a subject of open discussion. Throughout this review, we have provided numerous examples that indicate that sirtuinsespecially SirT1-have a dual role in cancer, operating as either tumor suppressors or as an oncogenic factor, depending on the scenario (Figure 3).

The possibility that SirT1 is a tumor suppressor is corroborated by its role in maintaining genome stability through chromatin regulation and DNA repair. ${ }^{3,57,60}$ Accordingly, SirT1 ${ }^{-/-}$mouse embryos exhibit more chromosomal aberrations and impaired DNA repair relative to WT embryos. ${ }^{16}$ Further evidence comes from mice containing a transgenic copy of SirT1 under its own regulatory elements (SirT1-tg mice), which exhibit global overexpression of SirT1 (at roughly 3 times normal levels). ${ }^{188}$ At old age, SirT1-tg mice are healthier than WT mice; however, this 
effect is not sufficiently potent to extend longevity. Moreover, SirT1-tg mice also show lower levels of DNA damage and decreased expression of the aging-associated gene p16 (Ink4a) and are partially protected from diabetes, osteoporosis, and cancer. ${ }^{188}$ In addition, SirT1-tg mice suffer less frequently from spontaneous carcinomas and sarcomas. Herranz et $a l^{188}$ developed a metabolic syndrome-associated liver cancer model in which SirT1-tg mice were less susceptible to liver cancer and exhibited greater hepatic protection from both DNA damage and metabolic damage relative to WT mice. These results support SirT1 tumor suppression activity in aging- and metabolic syndrome-associated cancer.

Alternatively, there is much evidence supporting a role for SirT1 in tumor initiation and progression-namely, in blocking senescence and apoptosis. First, SirT1 overexpression can block stress-induced apoptosis via chromatin structure modulation and via deacetylation of nonhistone proteins, including p53, FOXO, E2F1, Rb, BCL6, Ku70, and so on ${ }^{67,132,167}$ However, and rather counterintuitively, transgenic mice overexpressing SirT1 do not exhibit a greater incidence of tumor formation. ${ }^{189-191}$ Furthermore, SirT1 is upregulated in various cancers. ${ }^{60,76,133-135}$ As we described earlier, SirT1 expression and activity are regulated by several key factors in cancer. Deregulation of these factors could result in SirT1 overexpression or activation, suggesting that increased levels of SirT1 could be a consequence, rather than a cause, of cancer. One explanation for this is that, given SirT1's role in inhibition of senescence and apoptosis, some tumors could become addicted to SirT1, and therefore, SirT1 expression would be very important for tumor development. This scenario is supported by the observation that SirT1 is overexpressed in chemoresistant leukemia, neuroblastomas, osteosarcomas, and ovarian and breast cancer cells. Also, biopsies from cancer patients treated with chemotherapeutic agents exhibit higher SirT1 levels than do untreated samples. ${ }^{192}$ Furthermore, ectopic SirT1 overexpression induces P-glycoprotein expression and makes cancer cells resistant to the chemotherapy drug doxorubicin, whereas depletion of SirT1 by siRNA partially reverses the drug-resistant phenotype. ${ }^{192}$ Moreover, studies have shown that the sirtuin activator resveratrol has chemopreventive activity against various cancers, including leukemia, DMBA-induced mammary tumors (in rats), skin cancer, and prostate cancer. ${ }^{193-196}$

An oncogenic role for SirT1 is further supported by its link to tumor promotion, through its role in angiogenesis. Recent studies impute SirT1 as a key regulator of vascular endothelial homeostasis, which controls angiogenesis, vascular tone, and endothelial dysfunction. Potente et al. ${ }^{197}$ found an aberrant postnatal neovascularization response of endothelial-restricted SirT1 mutant mice in which the deacetylase domain of SirT1 was lacking. In addition, SirT1deficient zebrafish have exhibited vascular patterning defects and hemorrhages due to dysregulated endothelial sprouting and vessel navigation, related to regulation of the expression of multiple genes involved in vascular endothelial homeostasis and remodeling. ${ }^{197}$ Potente et al. ${ }^{197}$ determined that among these genes, the connection between FOXO1 and SirT1 is very important for regulation of postnatal angiogenesis. FOXO1 is highly expressed in the vascular endothelium and has been shown to be an essential negative transcriptional regulator of vessel formation. ${ }^{198-202}$ SirT1 can act as a repressor of FOXO1-dependent transcriptional activity in endothelial cells, and knockdown of FOXO1 partially rescues the inhibitory effects of SirT1 gene silencing on the angiogenic activity of endothelial cells; together, these findings indicate that SirT1 regulates endothelial angiogenic functions by modulating the transcriptional activity of FOXO1. ${ }^{197}$ Moreover, SirT1 has been shown to interact with and deacetylate endothelial nitric oxide synthase (eNOS), a major factor in maintaining vascular homeostasis, leading to enhanced nitric oxide (NO) production. ${ }^{203}$ eNOS-derived NO is essential for endothelial-dependent vasorelaxation and survival, migration, and postnatal neovascularization. ${ }^{204-207}$ Moreover, FOXO1 and FOXO3 have been shown to repress eNOS expression, suggesting crosstalk among SirT1, FOXO, and eNOS. ${ }^{200}$

Much remains to be established on how SirT1 exerts its multiple functions in cancer and on how these functions affect tumorigenesis. Current knowledge suggests (Figure 4) that under normal conditions, in response to stress or to DNA damage, SirT1 might promote cell survival via cell cycle arrest, DNA repair, or inhibition of apoptosis. If the stress signal becomes chronic or the levels of damage cross a certain threshold, then SirT1 could induce cell senescence. This scenario is supported by the finding that $\mathrm{SirT}^{-/-}$MEFs are resistant to senescence. However, following chronic stress or DNA damage, the loss of a tumor suppressor or of any other checkpoint-related factor could cause an imbalance in these regulatory processes and induce SirT1 overexpression beyond a critical limit. This in turn would agree with the drastic reduction in the very high levels of SirT1 protein in undifferentiated cells as differentiation progresses. As cancer development is involved in dedifferentiation of cells, it could imply restoration of SirT1 protein to predifferentiation levels. The aberrant overexpression of SirT1 would in turn contribute to transformation and tumor formation by promoting cell growth and inhibiting apoptosis. ${ }^{73-75,83,122}$

Although the roles of other sirtuins in cancer have not been extensively investigated, all current data suggest that SirT2 works as a tumor suppressor: it is downregulated in some cancers, and its loss compromises the mitotic checkpoint, contributing to genomic instability and tumorigenesis. ${ }^{137,140,141}$ Like SirT1, SirT3 apparently plays a dual function in cultured cells: under normal conditions it promotes apoptosis, ${ }^{56,62,208}$ 
A

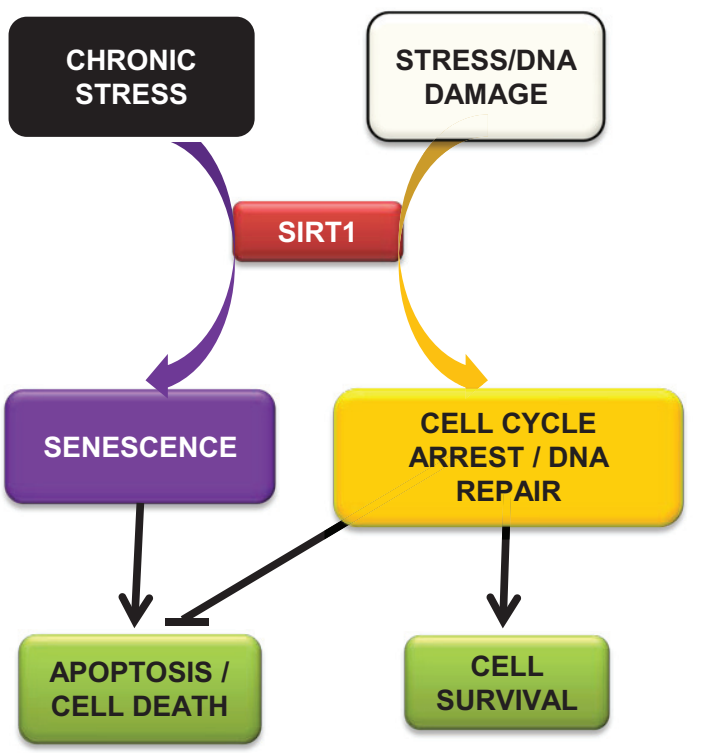

B

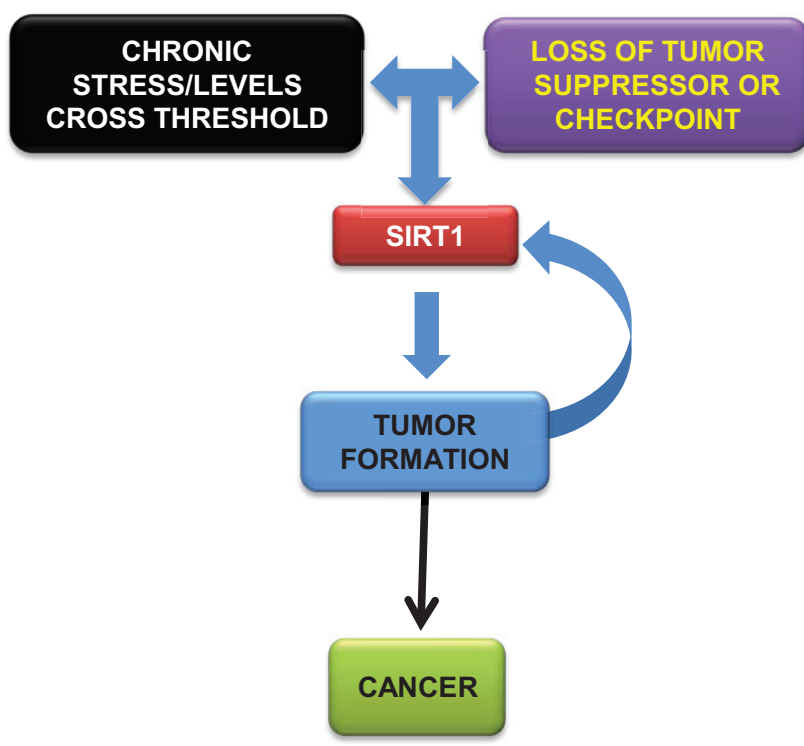

Figure 4. Model for SirT1 apparent duality in cancer. (A) Under stress conditions, SirT1 promotes cell cycle arrest, DNA repair, and, ultimately, cell survival. In chronic stress conditions or under certain massive levels of DNA damage, SirT1 induces senescence and apoptosis. (B) Under chronic stress and loss of tumor suppressors or checkpoints, SirT1 promotes tumor formation and cancer. A feedback between tumor progression and SirT1 levels is established, resulting in reinforced dedifferentiation, cell growth, and cell survival.

whereas under stress conditions, it seems to promote cell survival.

The mitochondrial sirtuins SirT4 and SirT5 do not seem to play an important part in cancer; nonetheless, this area requires further research.

As for SirT6, all evidence suggests that it acts as a tumor suppressor, given its major role as a guardian of genome stability. In addition, the SirT6 chromosomal locus (19p13.3) is a frequent breakage site in human acute myeloid leukemia. ${ }^{209}$ Moreover, the shift from aerobic respiration to glycolysis observed in SirT6-deficient mouse cells resembles the Warburg effect, in which cancer cells switch from oxidative phosphorylation to aerobic glycolysis. ${ }^{115,116}$

Finally, SirT7, which is localized in the nucleolus, seems to interact with and activate RNA polymerase I. ${ }^{210}$ However, SirT7 does not deacetylate RNA polymerase I; in fact, no substrates have yet been identified for this sirtuin. Given this finding, and the fact that SirT7 knockdown in human cells induces cell cycle arrest and apoptosis, ${ }^{208,211}$ further studies are definitely needed to determine its role in cancer.

\section{Final Remarks}

During the past decade, the members of the Sir2 family, known as sirtuins, have emerged as principal factors in sensing and regulating cellular response to oxidative and metabolic stress, compromising conditions that have been directly linked to tumorigenesis and tumor development. Although myriad questions regarding the roles of sirtuins in cancer remain unanswered, there is a growing body of evidence indicating that this research area should be prioritized. Future studies should indicate whether modulation of sirtuins could have implications for cancer treatment.

\section{Acknowledgments}

The authors thank Lourdes Serrano and members of the Vaquero group for fruitful discussions.

\section{Declaration of Conflicting Interests}

The authors declare that there are no potential conflicts of interest with respect to the authorship and/or publication of this article.

\section{Funding}

The Chromatin Biology group is supported by Spanish Ministry of Science and Innovation grant SAF2008-00923 and the Catalonian government agency AGAUR 2009SGR914. Alejandro Vaquero is an ICREA Researcher.

\section{References}

1. Shore D, Squire M, Nasmyth KA. Characterization of two genes required for the position-effect control of yeast mating-type genes. EMBO J 1984;3:2817-23.

2. Sinclair DA, Guarente L. Extrachromosomal rDNA circles - a cause of aging in yeast. Cell. 1997;91:1033-42.

3. Saunders LR, Verdin E. Sirtuins: critical regulators at the crossroads between cancer and aging. Oncogene. 2007;26:5489-504.

4. Guarente L. Diverse and dynamic functions of the Sir silencing complex. Nat Genet. 1999;23:281-5.

5. Braunstein M, Rose AB, Holmes SG, Allis CD, Broach JR. Transcriptional silencing in yeast is associated with reduced nucleosome acetylation. Genes Dev. 1993;7:592-604.

6. Vaquero A. The conserved role of sirtuins in chromatin regulation. Int J Dev Biol. 2009;53:303-22. 
7. Imai S, Armstrong CM, Kaeberlein M, Guarente L. Transcriptional silencing and longevity protein Sir2 is an NAD-dependent histone deacetylase. Nature. 2000;403:795-800.

8. Landry J, Sutton A, Tafrov ST, et al. The silencing protein SIR2 and its homologs are NADdependent protein deacetylases. Proc Natl Acad Sci U S A. 2000;97:5807-11.

9. Tanny JC, Dowd GJ, Huang J, Hilz H, Moazed D. An enzymatic activity in the yeast Sir2 protein that is essential for gene silencing. Cell. 1999;99:735-45

10. Frye RA. Characterization of five human cDNAs with homology to the yeast SIR2 gene: Sir2-like proteins (sirtuins) metabolize NAD and may have protein ADP-ribosyltransferase activity. Biochem Biophys Res Commun. 1999;260:273-9.

11. Frye RA. Phylogenetic classification of prokaryotic and eukaryotic Sir2-like proteins. Biochem Biophys Res Commun. 2000;273:793-8.

12. Haigis MC, Guarente LP. Mammalian sirtuinsemerging roles in physiology, aging, and calorie restriction. Genes Dev. 2006;20:2913-21.

13. Vaquero A, Sternglanz R, Reinberg D. NAD+dependent deacetylation of $\mathrm{H} 4$ lysine 16 by class III HDACs. Oncogene. 2007;26:5505-20.

14. Michishita E, Park JY, Burneskis JM, Barrett JC, Horikawa I. Evolutionarily conserved and nonconserved cellular localizations and functions of human SIRT proteins. Mol Biol Cell. 2005; 16:4623-35.

15. Vaquero A, Reinberg D. Sirtuins in biology and disease. Boca Raton, FL: CRC Press/Taylor \& Francis; 2008.

16. Wang RH, Sengupta K, Li C, et al. Impaired DNA damage response, genome instability, and tumorigenesis in SIRT1 mutant mice. Cancer Cell. 2008;14:312-23.

17. Mostoslavsky R, Chua KF, Lombard DB, et al. Genomic instability and aging-like phenotype in the absence of mammalian SIRT6. Cell. 2006; 124:315-29.

18. Negrini S, Gorgoulis VG, Halazonetis TD. Genomic instability - an evolving hallmark of cancer. Nat Rev Mol Cell Biol. 2010;11:220-8.

19. Peters AH, O'Carroll D, Scherthan H, et al. Loss of the Suv39h histone methyltransferases impairs mammalian heterochromatin and genome stability. Cell. 2001;107:323-37.

20. Vaquero A, Scher M, Lee D, Erdjument-Bromage H, Tempst P, Reinberg D. Human SirT1 interacts with histone $\mathrm{H} 1$ and promotes formation of facultative heterochromatin. Mol Cell. 2004;16:93-105.

21. Vaquero A, Scher M, Erdjument-Bromage H, Tempst P, Serrano L, Reinberg D. SIRT1 regulates the histone methyl-transferase SUV39H1 during heterochromatin formation. Nature. 2007; 450:440-4

22. Jenuwein $\mathrm{T}$, Allis $\mathrm{CD}$. Translating the histone code. Science. 2001;293:1074-80.

23. Murayama A, Ohmori K, Fujimura A, et al. Epigenetic control of rDNA loci in response to intracellular energy status. Cell. 2008;133:627-39.

24. Zhang Y, Wang J, Chen G, Fan D, Deng M. Inhibition of Sirt1 promotes neural progenitors toward motoneuron differentiation from human embryonic stem cells. Biochem Biophys Res Commun. 2011;404:610-4
25. Ou X, Chae HD, Wang RH, et al. SIRT1 deficiency compromises mouse embryonic stem cell hematopoietic differentiation, and embryonic and adult hematopoiesis in the mouse. Blood. 2011;117:440-50.

26. Saunders LR, Sharma AD, Tawney J, et al. miRNAs regulate SIRT1 expression during mouse embryonic stem cell differentiation and in adult mouse tissues. Aging (Albany NY). 2010;2:415-31.

27. Calvanese V, Lara E, Suarez-Alvarez B, et al. Sirtuin 1 regulation of developmental genes during differentiation of stem cells. Proc Natl Acad Sci U S A. 2010;107:13736-41.

28. Kuzmichev A, Margueron R, Vaquero A, et al. Composition and histone substrates of polycomb repressive group complexes change during cellular differentiation. Proc Natl Acad Sci U S A. 2005;102:1859-64.

29. Oberdoerffer P, Michan S, McVay M, et al. SIRT1 redistribution on chromatin promotes genomic stability but alters gene expression during aging. Cell. 2008;135:907-18.

30. Palacios JA, Herranz D, De Bonis ML, Velasco $\mathrm{S}$, Serrano M, Blasco MA. SIRT1 contributes to telomere maintenance and augments global homologous recombination. J Cell Biol. 2010;191:1299-313.

31. Bosch-Presegué L, Raurell-Vila H, MarazuelaDuque A, et al. Stabilization of Suv39h1 by SirT1 is part of oxidative stress response and ensures genome protection. Mol Cell. 2011;42:210-23.

32. Fraga MF, Ballestar E, Villar-Garea A, et al. Loss of acetylation at Lys 16 and trimethylation at Lys 20 of histone $\mathrm{H} 4$ is a common hallmark of human cancer. Nat Genet. 2005;37:391-400.

33. Pruitt K, Zinn RL, Ohm JE, et al. Inhibition of SIRT1 reactivates silenced cancer genes without loss of promoter DNA hypermethylation. PLoS Genet. 2006;2:e40.

34. Michishita E, McCord RA, Berber E, et al. SIRT6 is a histone $\mathrm{H} 3$ lysine 9 deacetylase that modulates telomeric chromatin. Nature. 2008;452:492-6.

35. Michishita E, McCord RA, Boxer LD, et al. Cell cycle-dependent deacetylation of telomeric histone $\mathrm{H} 3$ lysine $\mathrm{K} 56$ by human SIRT6. Cell Cycle. 2009;8:2664-6.

36. Yang B, Zwaans BM, Eckersdorff M, Lombard DB. The sirtuin SIRT6 deacetylates H3 K56Ac in vivo to promote genomic stability. Cell Cycle. 2009;8:2662-3.

37. Tennen RI, Chua KF. Chromatin regulation and genome maintenance by mammalian SIRT6. Trends Biochem Sci. 2011;36:39-46.

38. Das C, Lucia MS, Hansen KC, Tyler JK. CBP/ p300-mediated acetylation of histone $\mathrm{H} 3$ on lysine 56. Nature. 2009;459:113-7.

39. Vaquero A, Scher MB, Lee DH, et al. SirT2 is a histone deacetylase with preference for histone H4 Lys 16 during mitosis. Genes Dev. 2006;20:1256-61

40. Shogren-Knaak M, Ishii H, Sun JM, Pazin MJ, Davie JR, Peterson CL. Histone H4-K16 acetylation controls chromatin structure and protein interactions. Science. 2006;311:844-7.

41. Lombard DB, Alt FW, Cheng HL, et al. Mammalian Sir2 homolog SIRT3 regulates global mitochondrial lysine acetylation. Mol Cell Biol. 2007;27:8807-14
42. Scher MB, Vaquero A, Reinberg D. SirT3 is a nuclear NAD+-dependent histone deacetylase that translocates to the mitochondria upon cellular stress. Genes Dev. 2007;21:920-8.

43. McAinsh AD, Scott-Drew S, Murray JA, Jackson SP. DNA damage triggers disruption of telomeric silencing and Mec1p-dependent relocation of Sir3p. Curr Biol. 1999;9:963-6.

44. Martin SG, Laroche T, Suka N, Grunstein M, Gasser SM. Relocalization of telomeric $\mathrm{Ku}$ and SIR proteins in response to DNA strand breaks in yeast. Cell. 1999;97:621-33.

45. Shim EY, Hong SJ, Oum JH, Yanez Y, Zhang Y, Lee SE. RSC mobilizes nucleosomes to improve accessibility of repair machinery to the damaged chromatin. Mol Cell Biol. 2007;27:1602-13.

46. Mills KD, Sinclair DA, Guarente L. MEC1dependent redistribution of the Sir3 silencing protein from telomeres to DNA double-strand breaks. Cell. 1999;97:609-20.

47. Lee SE, Paques F, Sylvan J, Haber JE. Role of yeast SIR genes and mating type in directing DNA double-strand breaks to homologous and non-homologous repair paths. Curr Biol. 1999;9:767-70.

48. Tamburini BA, Tyler JK. Localized histone acetylation and deacetylation triggered by the homologous recombination pathway of double-strand DNA repair. Mol Cell Biol. 2005;25:4903-13.

49. Chen CC, Carson JJ, Feser J, et al. Acetylated lysine 56 on histone $\mathrm{H} 3$ drives chromatin assembly after repair and signals for the completion of repair. Cell. 2008;134:231-43.

50. Yuan Z, Zhang X, Sengupta N, Lane WS, Seto E. SIRT1 regulates the function of the Nijmegen breakage syndrome protein. Mol Cell. 2007;27:149-62.

51. Uhl M, Csernok A, Aydin S, Kreienberg R, Wiesmuller L, Gatz SA. Role of SIRT1 in homologous recombination. DNA Repair (Amst). 2010;9: 383-93.

52. Li K, Casta A, Wang R, et al. Regulation of WRN protein cellular localization and enzymatic activities by SIRT1-mediated deacetylation. J Biol Chem. 2008;283:7590-8.

53. Jeong J, Juhn $\mathrm{K}$, Lee H, et al. SIRT1 promotes DNA repair activity and deacetylation of $\mathrm{Ku} 70$. Exp Mol Med. 2007;39:8-13.

54. Sawada M, Sun W, Hayes P, Leskov K, Boothman DA, Matsuyama S. Ku70 suppresses the apoptotic translocation of Bax to mitochondria Nat Cell Biol. 2003;5:320-9.

55. Cohen HY, Miller C, Bitterman KJ, et al. Calorie restriction promotes mammalian cell survival by inducing the SIRT1 deacetylase. Science. 2004;305:390-2

56. Sundaresan NR, Samant SA, Pillai VB, Rajamohan SB, Gupta MP. SIRT3 is a stress-responsive deacetylase in cardiomyocytes that protects cells from stress-mediated cell death by deacetylation of Ku70. Mol Cell Biol. 2008;28:6384-401.

57. Fan W, Luo J. SIRT1 regulates UV-induced DNA repair through deacetylating XPA. Mol Cell. 2010;39:247-58.

58. McCord RA, Michishita E, Hong T, et al. SIRT6 stabilizes DNA-dependent protein kinase at chromatin for DNA double-strand break repair. Aging (Albany NY). 2009;1:109-21. 
59. Kaidi A, Weinert BT, Choudhary C, Jackson SP. Human SIRT6 promotes DNA end resection through CtIP deacetylation. Science. 2010;329:1348-53

60. Stunkel W, Peh BK, Tan YC, et al. Function of the SIRT1 protein deacetylase in cancer. Biotechnol J. 2007;2:1360-8.

61. Chua KF, Mostoslavsky R, Lombard DB, et al. Mammalian SIRT1 limits replicative life span in response to chronic genotoxic stress. Cell Metab. 2005;2:67-76

62. Allison SJ, Milner J. SIRT3 is pro-apoptotic and participates in distinct basal apoptotic pathways. Cell Cycle. 2007;6:2669-77

63. Wang F, Nguyen M, Qin FX, Tong Q. SIRT2 deacetylates FOXO3a in response to oxidative stress and caloric restriction. Aging Cell. 2007;6:505-14.

64. Langley E, Pearson M, Faretta M, et al. Human SIR2 deacetylates p53 and antagonizes PML/ p53-induced cellular senescence. EMBO J. 2002;21:2383-96.

65. Sasaki T, Maier B, Bartke A, Scrable H. Progressive loss of SIRT1 with cell cycle withdrawal. Aging Cell. 2006;5:413-22.

66. Ota $\mathrm{H}$, Tokunaga $\mathrm{E}$, Chang $\mathrm{K}$, et al. Sirt1 inhibitor, Sirtinol, induces senescence-like growth arrest with attenuated Ras-MAPK signaling in human cancer cells. Oncogene. 2006;25:176-85.

67. Luo J, Nikolaev AY, Imai S, et al. Negative control of p53 by Sir2alpha promotes cell survival under stress. Cell. 2001;107:137-48.

68. Vaziri $\mathrm{H}$, Dessain SK, Ng Eaton E, et al. hSIR2(SIRT1) functions as an NAD-dependent p53 deacetylase. Cell. 2001;107:149-59.

69. Hollstein M, Sidransky D, Vogelstein B, Harris CC. p53 mutations in human cancers. Science. 1991;253:49-53

70. Vogelstein B, Lane D, Levine AJ. Surfing the 553 network. Nature. 2000;408:307-10.

71. Lain S, Lane D. Improving cancer therapy by non-genotoxic activation of p53. Eur J Cancer. 2003;39:1053-60.

72. Cheng HL, Mostoslavsky R, Saito S, et al. Developmental defects and p53 hyperacetylation in Sir2 homolog (SIRT1)-deficient mice. Proc Natl Acad Sci U S A. 2003;100:10794-9.

73. Chen WY, Wang DH, Yen RC, Luo J, Gu W, Baylin SB. Tumor suppressor HIC1 directly regulates SIRT1 to modulate p53-dependent DNA-damage responses. Cell. 2005;123:437-48.

74. Kim JE, Chen J, Lou Z. DBC1 is a negative regulator of SIRT1. Nature. 2008;451:583-6.

75. Zhao W, Kruse JP, Tang Y, Jung SY, Qin J, Gu W. Negative regulation of the deacetylase SIRT1 by DBC1. Nature. 2008;451:587-90.

76. Lim CS. SIRT1: tumor promoter or tumor suppressor? Med Hypotheses. 2006;67:341-4.

77. Han MK, Song EK, Guo Y, Ou X, Mantel C, Broxmeyer HE. SIRT1 regulates apoptosis and Nanog expression in mouse embryonic stem cells by controlling p53 subcellular localization. Cell Stem Cell. 2008;2:241-51.

78. Kamel C, Abrol M, Jardine K, He X, McBurney MW. SirT1 fails to affect p53-mediated biological functions. Aging Cell. 2006;5:81-8.

79. Matsushita N, Takami Y, Kimura M, et al. Role of NAD-dependent deacetylases SIRT1 and SIRT2 in radiation and cisplatin-induced cell death in vertebrate cells. Genes Cells. 2005;10:321-32.
80. Li Y, Matsumori H, Nakayama Y, et al. SIRT2 down-regulation in HeLa can induce p53 accumulation via p38 MAPK activation-dependent p300 decrease, eventually leading to apoptosis. Genes Cells. 2011;16:34-45.

81. Li S, Banck M, Mujtaba S, Zhou MM, Sugrue MM, Walsh MJ. p53-induced growth arrest is regulated by the mitochondrial SirT3 deacetylase. PLoS One. 2010;5:e10486.

82. Talos F, Petrenko O, Mena P, Moll UM. Mitochondrially targeted p53 has tumor suppressor activities in vivo. Cancer Res. 2005;65:9971-81.

83. Greer EL, Brunet A. FOXO transcription factors at the interface between longevity and tumor suppression. Oncogene. 2005;24:7410-25.

84. Burgering BM, Kops GJ. Cell cycle and death control: long live Forkheads. Trends Biochem Sci. 2002;27:352-60

85. Accili D, Arden KC. FoxOs at the crossroads of cellular metabolism, differentiation, and transformation. Cell. 2004;117:421-6.

86. Furukawa-Hibi Y, Kobayashi Y, Chen C, Motoyama N. FOXO transcription factors in cellcycle regulation and the response to oxidative stress. Antioxid Redox Signal. 2005;7:752-60.

87. Barreyro FJ, Kobayashi S, Bronk SF, Werneburg NW, Malhi H, Gores GJ. Transcriptional regulation of Bim by FoxO3A mediates hepatocyte lipoapoptosis. J Biol Chem. 2007;282:27141-54.

88. Dehan E, Pagano M. Skp2, the FoxO1 hunter. Cancer Cell. 2005;7:209-10.

89. Fu Z, Tindall DJ. FOXOs, cancer and regulation of apoptosis. Oncogene. 2008;27:2312-9.

90. Galili N, Davis RJ, Fredericks WJ, et al. Fusion of a fork head domain gene to PAX3 in the solid tumour alveolar rhabdomyosarcoma. Nat Genet. 1993;5:230-5.

91. Parry P, Wei Y, Evans G. Cloning and characterization of the $t(X ; 11)$ breakpoint from a leukemic cell line identify a new member of the forkhead gene family. Genes Chromosomes Cancer. 1994;11:79-84.

92. Borkhardt A, Repp R, Haas OA, et al. Cloning and characterization of AFX, the gene that fuses to MLL in acute leukemias with a $t(X ; 11)$ (q13;q23). Oncogene. 1997;14:195-202.

93. Anderson MJ, Viars CS, Czekay S, Cavenee WK, Arden KC. Cloning and characterization of three human forkhead genes that comprise an FKHRlike gene subfamily. Genomics. 1998;47:187-99.

94. Brunet A, Sweeney LB, Sturgill JF, et al. Stressdependent regulation of FOXO transcription factors by the SIRT1 deacetylase. Science. 2004;303:2011-5.

95. Kobayashi Y, Furukawa-Hibi Y, Chen C, et al. SIRT1 is critical regulator of FOXO-mediated transcription in response to oxidative stress. Int J Mol Med. 2005;16:237-43.

96. van der Horst A, Tertoolen LG, de Vries-Smits LM, Frye RA, Medema RH, Burgering BM. FOXO4 is acetylated upon peroxide stress and deacetylated by the longevity protein hSir2(SIRT1). J Biol Chem. 2004;279:28873-9.

97. Matsuzaki H, Daitoku H, Hatta M, Aoyama H, Yoshimochi K, Fukamizu A. Acetylation of Foxo1 alters its DNA-binding ability and sensitivity to phosphorylation. Proc Natl Acad Sci U S A. 2005:102:11278-83.

98. Motta MC, Divecha N, Lemieux M, et al. Mammalian SIRT1 represses forkhead transcription factors. Cell. 2004;116:551-63.
99. Daitoku H, Hatta M, Matsuzaki H, et al. Silent information regulator 2 potentiates Foxo1-mediated transcription through its deacetylase activity. Proc Natl Acad Sci U S A. 2004;101:10042-7.

100. Yang Y, Hou H, Haller EM, Nicosia SV, Bai W. Suppression of FOXO1 activity by FHL2 through SIRT1-mediated deacetylation. EMBO J. 2005;24:1021-32.

101. Kuma A, Hatano M, Matsui M, et al. The role of autophagy during the early neonatal starvation period. Nature. 2004;432:1032-6.

102. Zhao Y, Yang J, Liao W, et al. Cytosolic FoxO1 is essential for the induction of autophagy and tumour suppressor activity. Nat Cell Biol. 2010;12:665-75.

103. Levine B. Cell biology: autophagy and cancer Nature. 2007;446:745-7.

104. Levine B, Kroemer G. Autophagy in the pathogenesis of disease. Cell. 2008;132:27-42.

105. Jacobs KM, Pennington JD, Bisht KS, et al. SIRT3 interacts with the daf-16 homo$\log$ FOXO3a in the mitochondria, as well as increases $\mathrm{FOXO} 3 \mathrm{a}$ dependent gene expression. Int J Biol Sci. 2008;4:291-9.

106. Ford J, Jiang M, Milner J. Cancer-specific functions of SIRT1 enable human epithelial cancer cell growth and survival. Cancer Res. 2005;65:10457-63.

107. Barnes PJ, Karin M. Nuclear factor-kappaB: a pivotal transcription factor in chronic inflammatory diseases. N Engl J Med. 1997;336:1066-71.

108. Pikarsky E, Porat RM, Stein I, et al. NF-kappaB functions as a tumour promoter in inflammation-associated cancer. Nature. 2004;431:461-6.

109. Yeung F, Hoberg JE, Ramsey CS, et al. Modulation of NF-kappaB-dependent transcription and cell survival by the SIRT1 deacetylase. EMBO J. 2004;23:2369-80.

110. Chen J, Zhou Y, Mueller-Steiner S, et al. SIRT1 protects against microglia-dependent amyloidbeta toxicity through inhibiting NF-kappaB signaling. J Biol Chem. 2005;280:40364-74.

111. Kiernan R, Bres V, Ng RW, et al. Post-activation turn-off of NF-kappa B-dependent transcription is regulated by acetylation of $\mathrm{p} 65 . \mathrm{J}$ Biol Chem. 2003;278:2758-66.

112. Rothgiesser KM, Erener S, Waibel S, Luscher B, Hottiger MO. SIRT2 regulates NF-kappaB dependent gene expression through deacetylation of p65 Lys310. J Cell Sci. 2010;123:4251-8.

113. Kawahara TL, Michishita E, Adler AS, et al. SIRT6 links histone H3 lysine 9 deacetylation to NF-kappaB-dependent gene expression and organismal life span. Cell. 2009;136:62-74.

114. Kaeberlein M, Kapahi P. The hypoxic response and aging. Cell Cycle. 2009;8:2324.

115. Denko NC. Hypoxia, HIF1 and glucose metabolism in the solid tumour. Nat Rev Cancer. 2008;8:705-13

116. Zhong L, D'Urso A, Toiber D, et al. The histone deacetylase Sirt6 regulates glucose homeostasis via Hiflalpha. Cell. 2010;140:280-93.

117. Singh KK. Mitochondria damage checkpoint, aging, and cancer. Ann N Y Acad Sci. 2006; 1067:182-90.

118. Kim SC, Sprung R, Chen Y, et al. Substrate and functional diversity of lysine acetylation revealed by a proteomics survey. Mol Cell. 2006;23:607-18 
119. Onyango P, Celic I, McCaffery JM, Boeke JD, Feinberg AP. SIRT3, a human SIR2 homologue, is an NAD-dependent deacetylase localized to mitochondria. Proc Natl Acad Sci U S A. 2002;99:13653-8.

120. Schwer B, North BJ, Frye RA, Ott M, Verdin E. The human silent information regulator (Sir)2 homologue hSIRT3 is a mitochondrial nicotinamide adenine dinucleotide-dependent deacetylase. J Cell Biol. 2002;158:647-57.

121. Kim HS, Patel K, Muldoon-Jacobs K, et al. SIRT3 is a mitochondria-localized tumor suppressor required for maintenance of mitochondrial integrity and metabolism during stress. Cancer Cell. 2010;17:41-52.

122. Dimova DK, Dyson NJ. The E2F transcriptional network: old acquaintances with new faces. Oncogene. 2005;24:2810-26.

123. Wong S, Weber JD. Deacetylation of the retinoblastoma tumour suppressor protein by SIRT1. Biochem J. 2007;407:451-60.

124. Logan CY, Nusse R. The Wnt signaling pathway in development and disease. Annu Rev Cell Dev Biol. 2004;20:781-810.

125. Korinek V, Barker N, Morin PJ, et al. Constitutive transcriptional activation by a beta-cateninTcf complex in APC-/- colon carcinoma. Science. 1997;275:1784-7.

126. Morin PJ, Sparks AB, Korinek V, et al. Activation of beta-catenin-Tcf signaling in colon cancer by mutations in beta-catenin or APC. Science. 1997:275:1787-90.

127. Brack AS, Conboy MJ, Roy S, et al. Increased Wnt signaling during aging alters muscle stem cell fate and increases fibrosis. Science. 2007;317:807-10.

128. Liu H, Fergusson MM, Castilho RM, et al. Augmented Wnt signaling in a mammalian model of accelerated aging. Science. 2007;317:803-6.

129. Firestein R, Blander G, Michan S, et al. The SIRT1 deacetylase suppresses intestinal tumorigenesis and colon cancer growth. PLoS One. 2008;3:e2020.

130. Wang RH, Zheng Y, Kim HS, et al. Interplay among BRCA1, SIRT1, and Survivin during BRCA1-associated tumorigenesis. Mol Cell. 2008;32:11-20.

131. Niu H. The proto-oncogene BCL-6 in normal and malignant B cell development. Hematol Oncol. 2002;20:155-66.

132. Heltweg B, Gatbonton T, Schuler AD, et al. Antitumor activity of a small-molecule inhibitor of human silent information regulator 2 enzymes. Cancer Res. 2006;66:4368-77.

133. Bradbury CA, Khanim FL, Hayden R, et al. Histone deacetylases in acute myeloid leukaemia show a distinctive pattern of expression that changes selectively in response to deacetylase inhibitors. Leukemia. 2005;19:1751-9.

134. Hida Y, Kubo Y, Murao K, Arase S. Strong expression of a longevity-related protein, SIRT1, in Bowen's disease. Arch Dermatol Res. 2007;299:103-6.

135. Huffman DM, Grizzle WE, Bamman MM, et al. SIRT1 is significantly elevated in mouse and human prostate cancer. Cancer Res. 2007; 67:6612-8.
136. Ashraf N, Zino S, Macintyre A, et al. Altered sirtuin expression is associated with node-positive breast cancer. Br J Cancer. 2006;95:1056-61.

137. Hiratsuka M, Inoue T, Toda T, et al. Proteomicsbased identification of differentially expressed genes in human gliomas: down-regulation of SIRT2 gene. Biochem Biophys Res Commun. 2003;309:558-66.

138. Inoue T, Hiratsuka M, Osaki M, et al. SIRT2, a tubulin deacetylase, acts to block the entry to chromosome condensation in response to mitotic stress. Oncogene. 2007;26:945-57.

139. Lennerz V, Fatho M, Gentilini C, et al. The response of autologous $\mathrm{T}$ cells to a human melanoma is dominated by mutated neoantigens. Proc Natl Acad Sci U S A. 2005;102:16013-8.

140. Dryden SC, Nahhas FA, Nowak JE, Goustin AS, Tainsky MA. Role for human SIRT2 NAD-dependent deacetylase activity in control of mitotic exit in the cell cycle. Mol Cell Biol. 2003;23:3173-85.

141. Inoue $T$, Hiratsuka $M$, Osaki $M$, Oshimura $M$ The molecular biology of mammalian SIRT proteins: SIRT2 in cell cycle regulation. Cell Cycle. 2007;6:1011-8.

142. Wales MM, Biel MA, el Deiry W, et al. p53 activates expression of HIC-1, a new candidate tumour suppressor gene on 17p13.3. Nat Med. 1995;1:570-7.

143. Chen W, Cooper TK, Zahnow CA, et al. Epigenetic and genetic loss of Hic1 function accentuates the role of p53 in tumorigenesis. Cancer Cell. 2004;6:387-98.

144. Chen WY, Zeng X, Carter MG, et al. Heterozygous disruption of Hicl predisposes mice to a gender-dependent spectrum of malignant tumors. Nat Genet. 2003;33:197-202.

145. Stankovic-Valentin N, Deltour S, Seeler J, et al. An acetylation/deacetylation-SUMOylation switch through a phylogenetically conserved psiKXEP motif in the tumor suppressor HIC1 regulates transcriptional repression activity. Mol Cell Biol. 2007;27:2661-75.

146. Caballero R, Setien F, Lopez-Serra L, et al. Combinatorial effects of splice variants modulate function of Aiolos. J Cell Sci. 2007;120:2619-30

147. Nemoto S, Fergusson MM, Finkel T. Nutrient availability regulates SIRT1 through a forkheaddependent pathway. Science. 2004;306:2105-8.

148. Lynch CJ, Shah ZH, Allison SJ, et al. SIRT1 undergoes alternative splicing in a novel auto-regulatory loop with p53. PLoS One. 2010;5:e13502.

149. Ambros V. The functions of animal microRNAs. Nature. 2004;431:350-5.

150. Bartel DP. MicroRNAs: genomics, biogenesis, mechanism, and function. Cell. 2004;116:281-97.

151. Caldas C, Brenton JD. Sizing up miRNAs as cancer genes. Nat Med. 2005;11:712-4.

152. Calin GA, Croce CM. MicroRNA signatures in human cancers. Nat Rev Cancer. 2006;6: $857-66$.

153. Cho WC. MicroRNAs: potential biomarkers for cancer diagnosis, prognosis and targets for therapy. Int J Biochem Cell Biol. 2010;42: 1273-81.
154. Esquela-Kerscher A, Slack FJ. OncomirsmicroRNAs with a role in cancer. Nat Rev Cancer. 2006;6:259-69.

155. Wittmann J, Jack HM. Serum microRNAs as powerful cancer biomarkers. Biochim Biophys Acta. 2010;1806:200-7.

156. Bommer GT, Gerin I, Feng Y, et al. p53-mediated activation of miRNA34 candidate tumorsuppressor genes. Curr Biol. 2007;17:1298-307.

157. He L, He X, Lim LP, et al. A microRNA component of the p53 tumour suppressor network. Nature. 2007;447:1130-4.

158. Raver-Shapira N, Marciano E, Meiri E, et al. Transcriptional activation of miR-34a contributes to p53-mediated apoptosis. Mol Cell. 2007;26:731-43.

159. Tarasov V, Jung P, Verdoodt B, et al. Differential regulation of microRNAs by $\mathrm{p} 53$ revealed by massively parallel sequencing: miR-34a is a p53 target that induces apoptosis and G1-arrest. Cell Cycle. 2007;6:1586-93.

160. Tazawa $H$, Tsuchiya $N$, Izumiya $M$, Nakagama $\mathrm{H}$. Tumor-suppressive miR-34a induces senescence-like growth arrest through modulation of the E2F pathway in human colon cancer cells. Proc Natl Acad Sci U S A. 2007;104:15472-7.

161. Yamakuchi M, Ferlito M, Lowenstein CJ. miR34a repression of SIRT1 regulates apoptosis. Proc Natl Acad Sci U S A. 2008;105:13421-6.

162. Chang TC, Wentzel EA, Kent OA, et al. Transactivation of miR-34a by p53 broadly influences gene expression and promotes apoptosis. Mol Cell. 2007;26:745-52.

163. Fujita Y, Kojima K, Hamada N, et al. Effects of miR-34a on cell growth and chemoresistance in prostate cancer PC3 cells. Biochem Biophys Res Commun. 2008;377:114-9.

164. Kojima K, Ohhashi R, Fujita Y, et al. A role for SIRT1 in cell growth and chemoresistance in prostate cancer PC3 and DU145 cells. Biochem Biophys Res Commun. 2008;373:423-8.

165. Akao Y, Noguchi S, Iio A, Kojima K, Takagi T, Naoe T. Dysregulation of microRNA-34a expression causes drug-resistance to 5 -FU in human colon cancer DLD-1 cells. Cancer Lett. 2011;300:197-204.

166. Xiong S, Salazar G, Patrushev N, Alexander RW. FoxO1 mediates an auto-feedback loop regulating SIRT1 expression. J Biol Chem. 2011;286:5289-99.

167. Wang C, Chen L, Hou X, et al. Interactions between E2F1 and SirT1 regulate apoptotic response to DNA damage. Nat Cell Biol. 2006;8:1025-31.

168. Martinez-Balbas MA, Bauer UM, Nielsen SJ, Brehm A, Kouzarides T. Regulation of E2F1 activity by acetylation. EMBO J. 2000;19:662-71.

169. Yuan J, Minter-Dykhouse K, Lou Z. A c-MycSIRT1 feedback loop regulates cell growth and transformation. J Cell Biol. 2009;185:203-11.

170. Abdelmohsen K, Pullmann R Jr, Lal A, et al. Phosphorylation of HuR by Chk2 regulates SIRT1 expression. Mol Cell. 2007;25:543-57.

171. Wang W, Yang X, Cristofalo VJ, Holbrook NJ, Gorospe M. Loss of HuR is linked to reduced expression of proliferative genes during replicative senescence. Mol Cell Biol. 2001;21:5889-98. 
172. Varambally S, Dhanasekaran SM, Zhou M, et al. The polycomb group protein EZH2 is involved in progression of prostate cancer. Nature. 2002;419:624-9.

173. Kleer CG, Cao Q, Varambally S, et al. EZH2 is a marker of aggressive breast cancer and promotes neoplastic transformation of breast epithelial cells. Proc Natl Acad Sci U S A. 2003;100:11606-11.

174. Kim EJ, Kho JH, Kang MR, Um SJ. Active regulator of SIRT1 cooperates with SIRT1 and facilitates suppression of $\mathrm{p} 53$ activity. Mol Cell. 2007;28:277-90.

175. Li Z, Chen L, Kabra N, Wang C, Fang J, Chen J. Inhibition of SUV39H1 methyltransferase activity by DBC1. J Biol Chem. 2009;284:10361-6.

176. Radvanyi L, Singh-Sandhu D, Gallichan S, et al. The gene associated with trichorhinophalangeal syndrome in humans is overexpressed in breast cancer. Proc Natl Acad Sci U S A. 2005;102:11005-10.

177. Trauernicht AM, Kim SJ, Kim NH, Boyer TG. Modulation of estrogen receptor alpha protein level and survival function by DBC-1. Mol Endocrinol. 2007;21:1526-36.

178. Fu J, Jiang J, Li J, et al. Deleted in breast cancer 1 , a novel androgen receptor (AR) coactivator that promotes AR DNA-binding activity. J Biol Chem. 2009;284:6832-40.

179. Lee H, Kim KR, Noh SJ, et al. Expression of DBC1 and SIRT1 is associated with poor prognosis for breast carcinoma. Hum Pathol. 2011;42:204-13.

180. Sung JY, Kim R, Kim JE, Lee J. Balance between SIRT1 and DBC1 expression is lost in breast cancer. Cancer Sci. 2010;101:1738-44.

181. Yang T, Sauve AA. NAD metabolism and sirtuins: metabolic regulation of protein deacetylation in stress and toxicity. Aaps J. 2006;8:E632-43.

182. Revollo JR, Grimm AA, Imai S. The NAD biosynthesis pathway mediated by nicotinamide phosphoribosyltransferase regulates Sir2 activity in mammalian cells. J Biol Chem. 2004;279:50754-63.

183. van der Veer E, Ho C, O'Neil C, et al. Extension of human cell lifespan by nicotinamide phosphoribosyltransferase. J Biol Chem. 2007;282:10841-5.

184. Wang B, Hasan MK, Alvarado E, Yuan H, Wu H, Chen WY. NAMPT overexpression in prostate cancer and its contribution to tumor cell survival and stress response. Oncogene. 2011;30:907-21.
185. McLure KG, Takagi M, Kastan MB. NAD+ modulates p53 DNA binding specificity and function. Mol Cell Biol. 2004;24:9958-67.

186. Zhang J. Are poly(ADP-ribosyl)ation by PARP-1 and deacetylation by Sir2 linked? Bioessays. 2003;25:808-14

187. Byles V, Chmilewski LK, Wang J, et al. Aberrant cytoplasm localization and protein stability of SIRT1 is regulated by PI3K/IGF-1R signaling in human cancer cells. Int J Biol Sci. 2010;6:599-612.

188. Herranz D, Munoz-Martin M, Canamero M, et al. Sirt1 improves healthy ageing and protects from metabolic syndrome-associated cancer. Nat Commun. 2010;1:1-8.

189. Banks AS, Kon N, Knight C, et al. SirT1 gain of function increases energy efficiency and prevents diabetes in mice. Cell Metab. 2008;8:333-41.

190. Pfluger PT, Herranz D, Velasco-Miguel S, Serrano $\mathrm{M}$, Tschop $\mathrm{MH}$. Sirt1 protects against high-fat diet-induced metabolic damage. Proc Natl Acad Sci U S A. 2008;105:9793-8.

191. Zhang QJ, Wang Z, Chen HZ, et al. Endothelium-specific overexpression of class III deacetylase SIRT1 decreases atherosclerosis in apolipoprotein E-deficient mice. Cardiovasc Res. 2008;80:191-9.

192. Chu F, Chou PM, Zheng X, Mirkin BL, Rebbaa A. Control of multidrug resistance gene mdr1 and cancer resistance to chemotherapy by the longevity gene sirt1. Cancer Res. 2005;65:10183-7.

193. Harper CE, Patel BB, Wang J, Arabshahi A, Eltoum IA, Lamartiniere CA. Resveratrol suppresses prostate cancer progression in transgenic mice. Carcinogenesis. 2007;28:1946-53.

194. Li T, Fan GX, Wang W, Li T, Yuan YK. Resveratrol induces apoptosis, influences IL-6 and exerts immunomodulatory effect on mouse lymphocytic leukemia both in vitro and in vivo. Int Immunopharmacol. 2007;7:1221-31.

195. Aziz MH, Afaq F, Ahmad N. Prevention of ultraviolet-B radiation damage by resveratrol in mouse skin is mediated via modulation in survivin. Photochem Photobiol. 2005;81:25-31.

196. Whitsett T, Carpenter M, Lamartiniere CA. Resveratrol, but not EGCG, in the diet suppresses DMBA-induced mammary cancer in rats. J Carcinog. 2006;5:15.

197. Potente M, Ghaeni L, Baldessari D, et al. SIRT1 controls endothelial angiogenic functions during vascular growth. Genes Dev. 2007;21:2644-58.

198. Furuyama T, Kitayama K, Shimoda Y, et al. Abnormal angiogenesis in Foxol (Fkhr)- deficient mice. J Biol Chem. 2004;279: 34741-9

199. Hosaka T, Biggs WH III, Tieu D, et al. Disruption of forkhead transcription factor (FOXO) family members in mice reveals their functional diversification. Proc Natl Acad Sci U S A. 2004;101:2975-80

200. Potente M, Urbich C, Sasaki K, et al. Involvement of Foxo transcription factors in angiogenesis and postnatal neovascularization. J Clin Invest. 2005;115:2382-92.

201. Paik JH, Kollipara R, Chu G, et al. FoxOs are lineage-restricted redundant tumor suppressors and regulate endothelial cell homeostasis. Cell. 2007;128:309-23.

202. Daly C, Wong V, Burova E, et al. Angiopoietin-1 modulates endothelial cell function and gene expression via the transcription factor FKHR (FOXO1). Genes Dev. 2004;18:1060-71.

203. Mattagajasingh I, Kim CS, Naqvi A, et al. SIRT1 promotes endothelium-dependent vascular relaxation by activating endothelial nitric oxide synthase. Proc Natl Acad Sci U S A. 2007; 104:14855-60.

204. Dimmeler S, Haendeler J, Nehls M, Zeiher AM. Suppression of apoptosis by nitric oxide via inhibition of interleukin-1beta-converting enzyme (ICE)-like and cysteine protease protein (CPP)32-like proteases. J Exp Med. 1997;185:601-7.

205. Potente M, Dimmeler S. Emerging roles of SIRT1 in vascular endothelial homeostasis. Cell Cycle. 2008;7:2117-22.

206. Aicher A, Heeschen C, Mildner-Rihm C, et al. Essential role of endothelial nitric oxide synthase for mobilization of stem and progenitor cells. Nat Med. 2003;9:1370-6.

207. Moncada S, Higgs A. The L-arginine-nitric oxide pathway. N Engl J Med. 1993;329:2002-12.

208. Rodriguez RM, Fraga MF. Aging and cancer: are sirtuins the link? Future Oncol. 2010;6: 905-15.

209. Mahlknecht U, Ho AD, Voelter-Mahlknecht S. Chromosomal organization and fluorescence in situ hybridization of the human Sirtuin 6 gene. Int J Oncol. 2006;28:447-56.

210. Ford E, Voit R, Liszt G, Magin C, Grummt I, Guarente L. Mammalian Sir2 homolog SIRT7 is an activator of RNA polymerase I transcription. Genes Dev. 2006;20:1075-80.

211. Vakhrusheva O, Smolka C, Gajawada $\mathrm{P}$, et al. Sirt7 increases stress resistance of cardiomyocytes and prevents apoptosis and inflammatory cardiomyopathy in mice. Circ Res. 2008; 102:703-10. 